\title{
ANOMALOUS ANATOMY OF IDENTIFIED NEURONS IN THE LARVAL PRAWN: SPONTANEOUS AND INDUCED BY MICROLESIONS ${ }^{1}$
}

\author{
DAVID R. FRIEDLANDER ${ }^{2}$ AND CYRUS LEVINTHAL \\ Department of Biological Sciences, Columbia University, New York, New York 10027 \\ Received April 23, 1981; Revised September 30, 1981; Accepted September 30, 1981
}

\begin{abstract}
The abdominal ganglia of the prawn Macrobrachium rosenbergii undergo developmental changes of fundamental interest between the time of hatching and metamorphosis. These changes include an increase in cell numbers and changes in the connectivity between identified neurons. The giant motoneurons involved in the escape response, which form a syncytium in the adult, are observed as separate neurons with crossed axons in early larvae.

Anomalous growth and connections of identified neurons were studied in order to gain some understanding of the rules and mechanisms governing normal development. Spontaneous anomalies included: supernumerary axons and abnormal axonal trajectories. The plasticity and specificity of identified neurons were studied by following the anatomical effects of deletions of giant neurons. Microlesions were inflicted reproducibly by means of a focused beam of visible and ultraviolet light. Within a day, irradiated cell bodies are eliminated; complete disappearance of the axon takes about 10 days, indicating that the remarkable ability of some invertebrate neurons to survive without a soma is not present in the larval prawn. As a result of the removal of an axon, the most common effect found in central connections was the absence of the collaterals or axons deprived of their targets. No collateral sprouting was detected in the central nervous system. In about a third of the ganglia where a giant motoneuron was killed and structure was analyzed 2 or more weeks after irradiation, anomalous connections were found. They usually involved contacts between an interneuron deprived of its normal target and the contralateral motoneuron which remained intact. The restricted types of anomalies observed support the notion of a hierarchical order in the rules governing formation of central synapses, in which neuron type ranks higher than laterality.
\end{abstract}

Decapod crustaceans, such as crayfish and lobsters, have been animals of choice of neurobiologists for many years. The main reason for this is their relatively simple nervous system; the fact that several of their cells are remarkably large and can be identified according to a variety of anatomical and physiological criteria is also a contributing factor in their choice. The giant Malaysian prawn, Macrobrachium rosenbergii, shares the advan-

\footnotetext{
This work was supported by National Institutes of Health Grants NS 09821 and RR-00442. We thank D. Soroker and M. Spira for kindly letting us know details of their unpublished observations on the connectivity of the giant fibers of the adult prawn. We also thank A. F. Eble (Rutgers University and Public Service Electric and Gas Co., NJ) and Paul Sandifer and Frank Taylor (Marine Resources Institute, Charleston, SC) for providing us with animals for our breeding stock and for valuable information on how to grow the prawn.

${ }^{2}$ To whom correspondence should be addressed at his present address: Department of Neuroscience, Albert Einstein College of Medicine, 1300 Morris Park Avenue, Bronx, NY 10461.
}

tages offered by other Decapoda, since many of the features of the adults are similar to those studied in crayfish and lobster. However, it is better suited for developmental studies for several reasons: (1) culturing methods are well developed due to the importance of this animal as a food resource (Ling, 1962, 1967); (2) the brood size is enormous, with an adult female laying more than 20,000 viable eggs simultaneously as a result of a single mating; and (3) it hatches as a swimming larva, which is significantly different from the adult in gross anatomy, neuroanatomy, and behavior. This facilitates experimental studies of the developing nervous system, since larvae are much easier to work with than embryos.

Macrobrachium rosenbergii goes through 11 stages, during which its length increases from 2 to $8 \mathrm{~mm}$. The stages are separated by successive molts, which, at $28^{\circ} \mathrm{C}$, occur every other day during the first 5 stages and at longer intervals during the later stages. After the 11th larval stage, which is about 30 to 40 days post-hatching, the animal undergoes a metamorphosis. The postlarval 
animal is about $8 \mathrm{~mm}$ long and is similar in general anatomy and swimming and locomotion behaviors to the adult, which can reach sizes of more than $20 \mathrm{~cm}$. Sexual maturity is reached approximately 7 months after hatching (Ling, 1962, 1967; Uno and Kwon Chin Soo, 1969).

For the most part, experimental investigation of the formation of nerve connections of identified neurons has been limited to the study of regenerating cells. Such studies have shown that identified invertebrate neurons are capable of re-establishing specific connections (Hoy et al., 1967; Baylor and Nicholls, 1971; Jansen and Nicholls, 1972; Pearson and Bradley, 1972; Jansen et al., 1974; Muller and Carbonetto, 1979; Murphy and Kater, 1978,1980 ), although the final situation can be preceded by a period in which nonspecific synapses are formed and subsequently eliminated (Denburg et al., 1977; Whitington, 1979).

Studies on developing invertebrates have shown that the normal specific reinnervation can be impeded by removing the afferents of an identified target or by selectively preventing their regeneration (Edwards and Palka, 1973; Palka and Edwards, 1973; Murphey and Levine, 1980). Although it is clear that establishing a specific connection requires a chemical compatibility between the cells involved, an organized pattern can be formed without relying on specific chemical markers. Studies using a UV microbeam to delete selectively small numbers of cells suggest that identified retinula cells in the developing water flea select their targets from anong a population of lamina cells according to their time of differentiation and the position that they have at the time of contact (LoPresti et al., 1973; Macagno, 1978). It is possible to remove single identified neurons by injecting them with pronase (Parnas and Bowling, 1977; Bowling et al., 1978) or by light irradiation of a cell filled with Lucifer yellow (Miller and Selverston, 1979). However, enzyme or dye injection is difficult in the small cells of embryonic tissue.

In this paper, we describe alterations produced in the connections between developing neurons when microlesions remove one or more identified cells. We also describe anomalies in the morphology of giant axons which were encountered occasionally during the course of the work. The effects of the lesions on the neuromuscular connections (Friedlander and Levinthal, 1980) will be the central subject of a future paper. The objective of these studies is to gain understanding of the rules and mechanisms underlying normal development.

An abstract of part of this work has been published previously (Friedlander and Levinthal, 1979).

\section{Materials and Methods}

Animal care. Aquaculture procedures are basically those developed by Ling $(1962,1967)$. Animals are kept in 10- to 60-gallon aquaria placed in an environmental room where the ambient temperature is set in such a way that water temperature is maintained at $28.5 \pm 1^{\circ} \mathrm{C}$. Male to female ratio in the stock brood is about $1: 3$. Fertile females are taken within $24 \mathrm{hr}$ of a premating molt and kept in an aquarium containing only one male. Two to 3 days before a hatch intended for culturing purposes, the female is introduced into a tank containing water at a $0.7 \%(\mathrm{w} / \mathrm{v})$ sea salt (Instant Ocean) concentration. Newly hatched 1st stage larvae are introduced into larval water (1.2\% sea salts) after acclimatization in $1 \%$ sea salt water. Approximately 700 animals are put in the larval tank. Juvenile and adult animals are fed thawed frozen fish and spinach, alternating daily with Purina Marine Ration 25 (Ralston Purina, New Venture Management), and fresh carrots. Larvae are fed live Artemia (brine shrimp) daily, which, after the 1st week, is supplemented with small fragments of egg custard, four to six times a day.

Experimental larvae requiring individual or group identification are grown initially in 100-ml Petri dishes, following the same acclimatization schedule and receiving the same food, although only once daily, as mass grown animals. During the first 5 to 10 days, irradiated larvae are kept in the dark in order to eliminate any possible light repair of the UV damage (Jagger, 1967); water and food are changed under a red light. After 10 to 15 days, experimental larvae are transferred from the Petri dishes to small submerged cages through which water circulates continuously. The same procedures are followed with control larvae, which have not suffered irradiation, in order to check if the irradiation alters the survival rate of the animals.

Histology and ultrastructure. After immobilization in cold saline, larvae are staged under a dissecting microscope according to an 11-stage classification (Uno and Kwon Chin Soo, 1969). Early stage larvae are pinned down on dental wax with stainless steel needles. The carapace in the thoracic region is damaged with No. 5 forceps to allow penetration of the fixative solution. Later stage larvae are pinned down on a Sylgard-lined dish and the whole ventral side of the carapace is removed. Then they are pinned on dental wax and submerged in the fixative solution. In adults, the abdominal cord is dissected out in cold aquarium water and similarly transferred to a piece of dental wax prior to fixation. The composition of the fixative used for animals which were cut in serial sections consisted of: $1 \%$ osmium tetroxide, $0.1 \mathrm{M}$ sodium cacodylate, $\mathrm{pH} 7.5$, full strength crayfish Ringer solution (van Harrevald, 1936). Fixation time was $2 \mathrm{hr}$ at $4^{\circ} \mathrm{C}$. Material analyzed in whole mounts was fixed

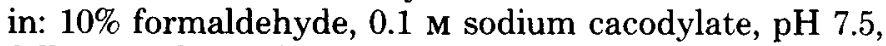
full strength crayfish Ringer solution, with a fixation time of 1 day to several weeks at $4^{\circ} \mathrm{C}$. After fixation, the thorax and the posterior end of the abdomen were removed to facilitate dehydration and infiltration of the embedding medium.

Light and electron microscopy were done on thin (1$\mu \mathrm{m})$ and ultrathin $(0.1-\mu \mathrm{m})$ sections cut with a diamond knife from blocks of tissue dehydrated in acetone and embedded in Epon. Ultrathin sections were stained at room temperature in $2 \%$ uranyl acetate for $15 \mathrm{~min}$ and then washed and further stained with Reynold's (1963) lead citrate. Thin $1-\mu \mathrm{m}$ sections were stained for light microscopy (LM) on a hot plate with $1 \%(\mathrm{w} / \mathrm{v})$ toluidine blue and $1 \%$ borax in distilled water. Interference Nomarski optics were used to increase detail while looking at these sections. Whole mounts were prepared from larvae treated with Feulgen's method (Leuchtenberger, 1958) to stain nuclei selectively. Acid hydrolysis was 
applied for $3 \mathrm{~min}$ at $55^{\circ} \mathrm{C}$. The material was embedded in ultra low viscosity embedding medium (Ladd) from which slabs containing the ventral cord were cut.

Cell counts. Two different methods were used to count cells. In ganglia of adults, counts were made from filmstrips of photographs from $1-\mu \mathrm{m}$ serial sections, aligned, and analyzed with the CARTOS system (Levinthal et al., 1976). In larvae, cells are counted directly from the whole mount with the help of a small computer, Tektronix 4051, which stores the $x, y$, and $z$ coordinates of a nuclear center as indicated by the investigator during observation through a light microscope (see Macagno et al., 1979; Macagno, 1980, for details of this system). Each ganglion is analyzed twice, at different sessions, to determine the reliability of the method. When using whole mounts, where the question of overlap was somewhat ambiguous, a simple computer program gives the number of cells after eliminating any points closer than $2.5 \mu \mathrm{m}$ to a nuclear center previously recorded.

Lesions. Microlesions are produced by focusing a UVcontaining light beam on a small region of the ganglion. The apparatus is basically an American Optical fluorescence microscope fitted with a Beck and Beck $\times 36$ reflecting objective. Irradiation is done from the top with an Osram 50-W AC high pressure mercury lamp, which has a broad light spectrum reaching the far UV and emanating from a small bright spot. A quartz condenser images the source on a pinhole, producing a secondary source of controllable size, which is focused on the region of interest by the reflecting objective. With this arrangement, the damage is produced by a cone of light of 0.4 numerical aperture with a cross-section at its vertex that can be adjusted from 1 to $20 \mu \mathrm{m}$ or more. The same apparatus has been used to produce microlesions in the eye of the water flea, Daphnia magna (Macagno, 1977, 1978,1979 ). 'The animal is placed submerged in a modified Sykes Moore chamber (Bellco Glass, Inc.), ventral side up, facing the damaging beam with the abdomen in contact with a quartz coverslip. The larva is kept in place by one or two eyelashes, acting as a spring (Fig. $7 A$ ). Low temperature $\left(10^{\circ} \mathrm{C}\right)$ helps to keep the animal from moving or escaping.

Viewing is also done from the top, with illumination provided by a standard understage condenser. The animal is sufficiently transparent for one to see the contour of the abdominal cord with ease and, with more difficulty, some cells in the ganglion. Since it was not possible to localize the individual giant motoneurons (GMNs) visually, the beam was directed toward a region of the ganglion where the GMN was expected to be, according to previous histological observations. We prepared a mask consisting of a properly scaled photograph of a drawing of the contour of an average 2 nd abdominal ganglion, including the position of the GMN nuclei. In preparing the drawing, we averaged the position of these nuclei and the contours of the 2nd abdominal ganglia of three 1st stage larvae obtained from whole mounts of tissue fixed in formalin. The resulting diagram was averaged with a mirror image version of it to provide a final bilaterally symmetrical drawing. A similar mask was constructed for the 3rd abdominal ganglion.

The nuclei of the GMNs in the original whole mounts were found to be within a 5- $\mu \mathrm{m}$ distance of the average position. (It is more difficult to establish the accuracy of our estimation of the GMN position in the live animal.) The microlesion is produced by moving the microscope stage until the ganglion fits the photographic mask, which is placed in the eyepiece reticle plane, parfocal with the vertex of the light cone effecting the lesion. Once the animal is positioned, the ganglion is irradiated for $2 \mathrm{~min}$. The radiation dosage necessary to delete a GMN consistently with this procedure also kills other cells within a region of about $20 \mu \mathrm{m}$ diameter. Consequently, the experiments fall short of eliminating only 1 cell, an ideal objective which cannot be attained without actually seeing the GMN.

Statistics. The data have been analyzed with Fisher's exact test, which is especially appropriate for low expected frequencies. We usually express the effect of microlesions in two different forms: (1) number of anomalies divided by the maximum number of opportunities to observe such an anomaly. The probability calculated in the statistical test for this form will be labeled $p(c)$, where " $c$ " stands for "contact." $p(c)$ is most meaningful if the occurrences of anomalous contacts are independent and equally probable. (2) The number of ganglia with one or two anomalies ("anomalous ganglia" in short) also were analyzed. The probability given by the test for this form will be abbreviated as $p(g)$, where " $g$ " stands for "ganglion." $p(g)$ is most meaningful if anomalies usually occur together. It is apparent from the data that there is a partial correlation between the two anomalies studied (contralateral lateral giant (LG)- and medial giant (MG)GMN). On the other hand, the data suggest that MGGMN anomalous contacts are more frequent than atypical LG-GMN contacts. Thus, we encounter a situation intermediate between the ones defined by the assumptions in forms 1 and 2 . Consequently, we will assume that, in a best estimation, the probability that the observed results could have been obtained by chance alone will lie between $p(c)$ and $p(g)$.

\section{Results}

\section{Normal development}

Cell numbers. We counted the numbers of cells in the 2nd abdominal ganglia of different stage larvae and compared them to a count made in the same ganglion of a 5cm-long juvenile ( $\sim 6$ months old). Six siblings were used in the early larval stages count: four in the 1st post-hatch day (2 mm long) and two 7-day-old 5th stage larvae (3 $\mathrm{mm}$ long). In each case, animals were fixed within an interval of $30 \mathrm{~min}$. One ganglion was counted at the 10th stage ( $7 \mathrm{~mm}$ long, $\sim 30$ days old).

Only cells with light nuclei exhibiting prominent nucleoli were counted as neurons in the juvenile (Fig. 1, $C$ and $D)$. When some of these cells were examined carefully, they showed neurites. Counts were made from a filmstrip of aligned photographs of $1-\mu \mathrm{m}$-thick serial sections. We did not attempt to count the numerous glia of the adult ganglia. The smaller size of the larval ganglia permitted us to count cells directly from whole mounts (Fig. $1 B$ ). Larval cells were classified as glia or neurons according to the position and morphology of their nuclei 

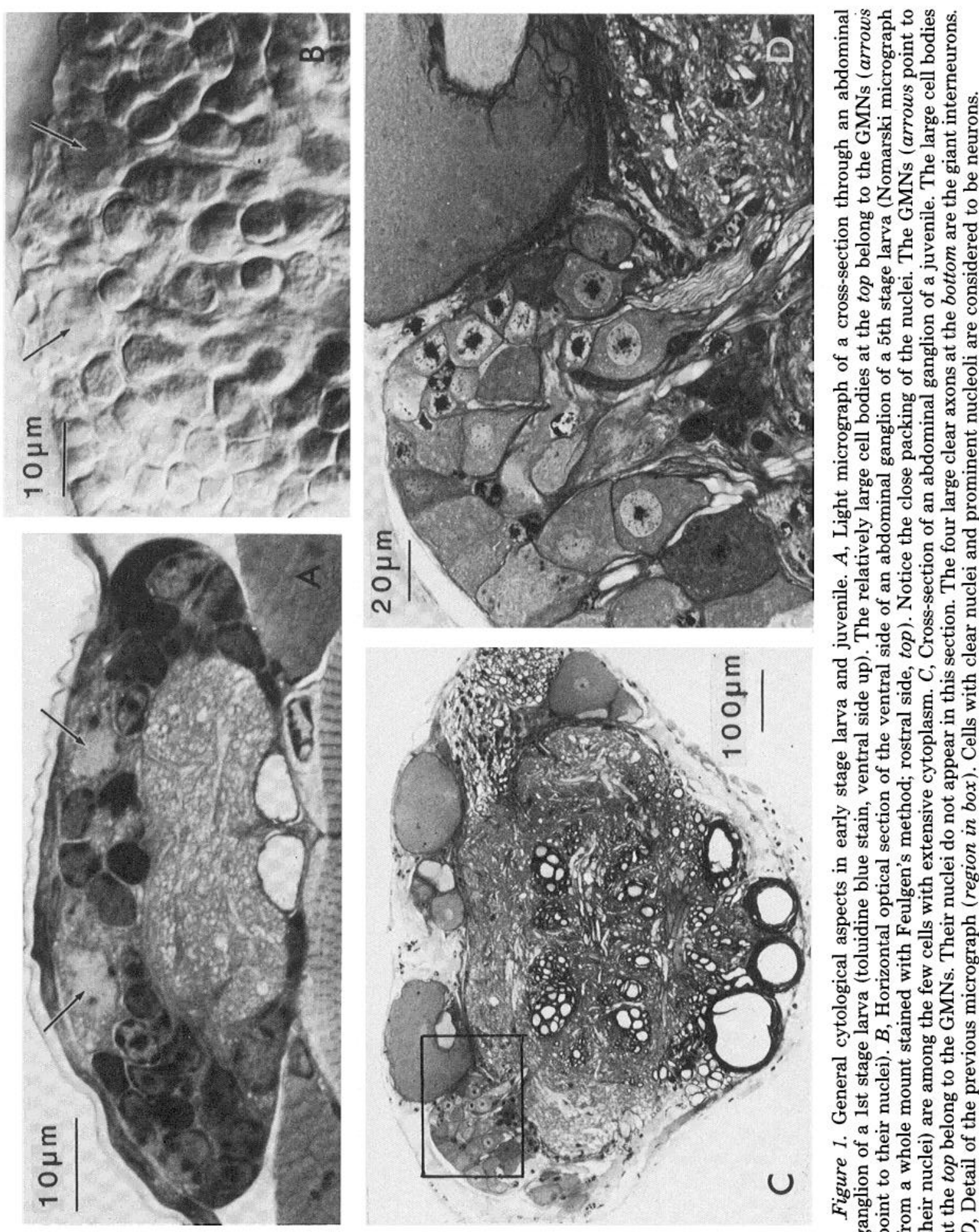

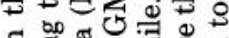

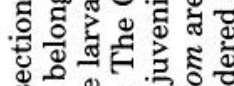
क.

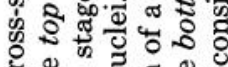

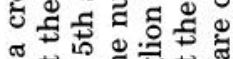
$\widetilde{\omega} \pi \pm$

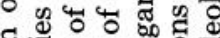
:

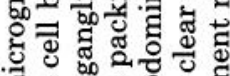
दี $₫$ 요

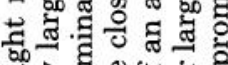

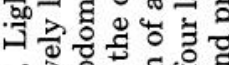

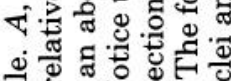

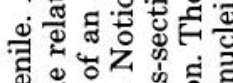
व

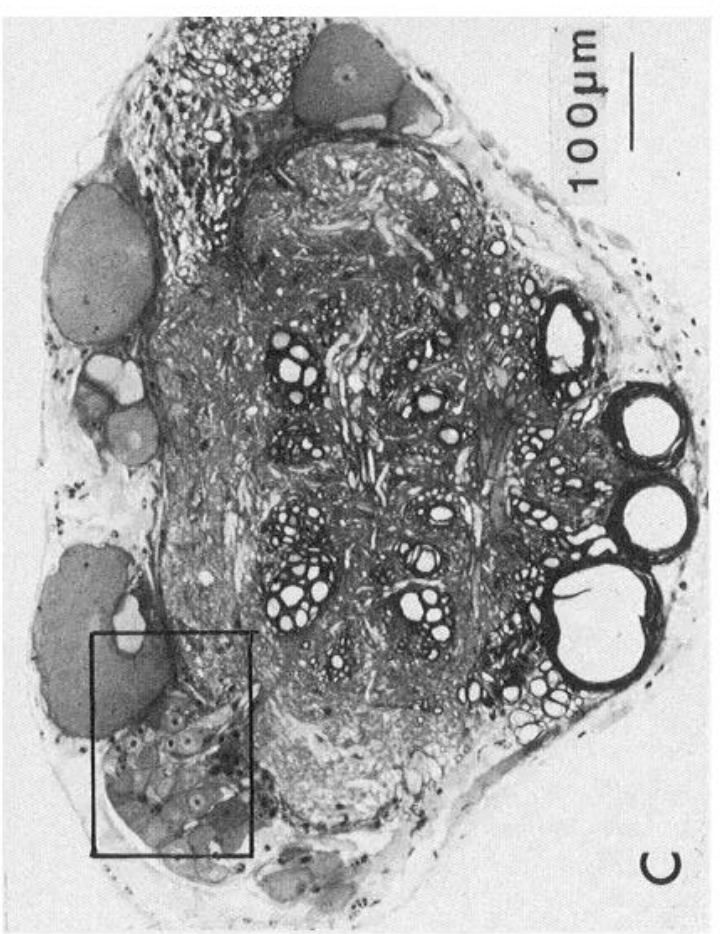

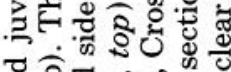

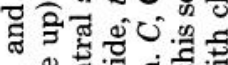
๘

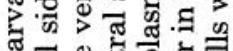
ส]

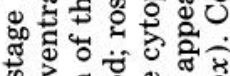
का 겸웜

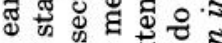

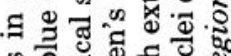

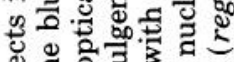

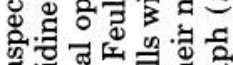

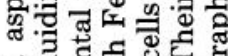
बु \%

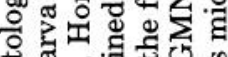
ț ०ै ๘ึ ปั ธ.

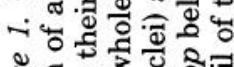
ง ำ 30.

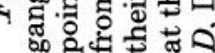


(Fig. 1A). Only nuclei of irregular form, in cells surrounding axons, could be recognized unequivocally as glia. The rest of the cells were counted as neurons. These criteria probably exaggerate the number of neurons in our counts of larval cells. In the younger animals, we counted each ganglion twice, in order to distinguish between animal to animal variations and uncertainties originating in the counting procedure.

As seen in Table I, the number of neurons increases by a factor of about 3 from the 1st to the 10th larval stage. During the same period, the number of glia increases by approximately a factor of 30 . Only a small increase in the number of neurons is noticed between the 10th larval stage and the juvenile. Glia continue to proliferate after metamorphosis. In early larvae, where we recorded less than $10 \%$ glia, the number of neurons may be exaggerated but is certainly less than the total number of counted cells. In the juvenile, the neurons may be undercounted, since we require the appearance of distinct nucleoli to classify a cell as a neuron. Therefore, the increase of approximately 3 -fold in the number of neurons per ganglion is a lower estimate of the true increase.

No mitotic figures were observed in the 7 larval abdominal ganglia where counts were made nor did we see any mitosis in the rest of the approximately 100 Feulgenstained ganglia used in our studies. If we assume that all mitoses occur locally in the ganglia and are distributed randomly in time and further assume that metaphase lasts at least $10 \mathrm{~min}$ (Jacobson, 1978, p. 34), it is simple to estimate that we should have seen more than 25 mitotic cells in metaphase, since the average number of cells which are added in the 7 days between the 1st and 5 th stages is about 250 . From the lack of any observed metaphase cells, we conclude that one or more of the assumptions used to estimate the expected number of mitotic figures must be in error. New cells may migrate into the ganglion from the outside, metaphase may take much less than 10 min, or the mitoses are synchronized in time, perhaps timed in relation to the larval molts.

TABLE I

Cell numbers in a 2nd abdominal ganglion

A summary of cell counts in the 2nd abdominal ganglia at different stages of development is given.

\begin{tabular}{|c|c|c|c|c|}
\hline Specimen & Stage & Neurons & Glia & Total \\
\hline 102 & 1 & $287 \quad(3)^{a}$ & $22 \quad(2)$ & $309 \quad(5)$ \\
\hline 103 & 1 & $282 \quad(7)$ & $14.5(1.5)$ & $296.5(8.5)$ \\
\hline 116 & 1 & $268.5(7.5)$ & $24 \quad$ (2) & $292.5(5.5)$ \\
\hline 118 & 1 & 294.5 (1.5) & $18.5(1.5)$ & $313 \quad(3.0)$ \\
\hline Mean & 1 & $283 \quad(9.5)^{b}$ & $19.8(3.6)$ & $302.3(8.5)$ \\
\hline 504 & 5 & $512.5(2.5)^{a}$ & $36 \quad(0)$ & $548.5(2.5)$ \\
\hline 517 & 5 & $457 \quad(10)$ & $26 \quad(0)$ & $483 \quad(10)$ \\
\hline Mean & 5 & $484.8(27.8)^{b}$ & $31 \quad$ (5) & $515.8(32.8)$ \\
\hline 1001 & 10 & 834 & 679 & 1513 \\
\hline VC162 & juvenile & 886 & & \\
\hline
\end{tabular}

"Average of two counts on the same speciment. The number in parentheses is the sample variance.

${ }^{b}$ Mean of the averages listed above. In parentheses, the sample variance of averages is given.
However, this phenomenon has not been investigated further.

Identified neurons. The morphology of the giant axons in the 3 rostral abdominal ganglia of the late larva (Fig. 2 ) is basically the same as that of the adult prawn. The connectivity differs from that of the crayfish in two major aspects: (1) the 2 giant motoneurons (GMNs) in the prawn are fused so that they share a common cytoplasm (Johnson, 1924; Macagno and Friedlander, 1976); in the crayfish, they are separate cells. (2) In the prawn, the medial giant (MG) connects exclusively with the ipsilateral axon (Holmes, 1942); in crayfish, the MG synapses with both GMNs (Wiersma, 1947; Selverston and Kennedy, 1969). Interestingly, the connectivity of the giant fibers in the early larval prawn resembles that of the adult crayfish.

Early larva: GMN fusion. Analyses of serially sectioned ganglia show that, during the earlier larval stages, the GMNs are not fused (Fig. $3 A$ ) as they are in the adult. Axons exit through the fourth roots (which correspond to the third roots in crayfish) contralaterally to their somata, after traveling side by side over a considerable distance in the ganglion. This form of development for syncytial neurons, through the anastomosis of separate cells, is analogous to that of the first order giant fibers in the squid (Young, 1939).

The fusion between the GMNs occurs at about the 7th or 8th larval stage, although there is a considerable variation in this timing: fused GMNs were observed as early as in the 6th stage, while unfused pairs were detected as late as in the 11th stage. At the time of anastomosis and during a few larval stages, the region of fusion is localized to a distance of a few micrometers along the axons in the vicinities of the fourth roots. This site coincides with the position of an identifiable glial cell which has a nucleus resembling a flattened pyramid (Fig. $3 C$ ). Eventually, in the adult, the extent of the anastomosis is much greater, reaching from the point where the GMNs meet in the ganglion to the fourth root region, where they split again before leaving the ventral cord to innervate the flexor muscles.

Interneurons. At hatching time, the MGs can be recognized by virtue of being large axons in the mediodorsal side of the connective and by their typical contact with the GMNs. The lateral giants (LGs) also can be identified by their prominent size and location but only in the connective between the 4th and 5th abdominal ganglia. Their contact (by "contact" we mean an apposition between an axon terminal and another neurite as seen with the light microscope, e.g., Fig. 2, $F$ and $G$ ) with the 4 th ganglion GMNs is easily observed. The LG reduces its size rostral to the fourth root region of the 4th ganglion and appears to taper off. Using electron microscopy, we were able to demonstrate the presence of $L G$ axons by their position and typical contact with the GMN in the fourth root region of the 3 anterior abdominal ganglia (Fig. $4 C$ ). This could be done even in 14-day-old embryos, which is 5 days before the time of hatching. We do not know whether segmental LG elements are in contact with each other at the 1st larval stage. The complete lateral giant system is visible under the optical microscope at the 4th larval stage, about 6 days after hatching. 

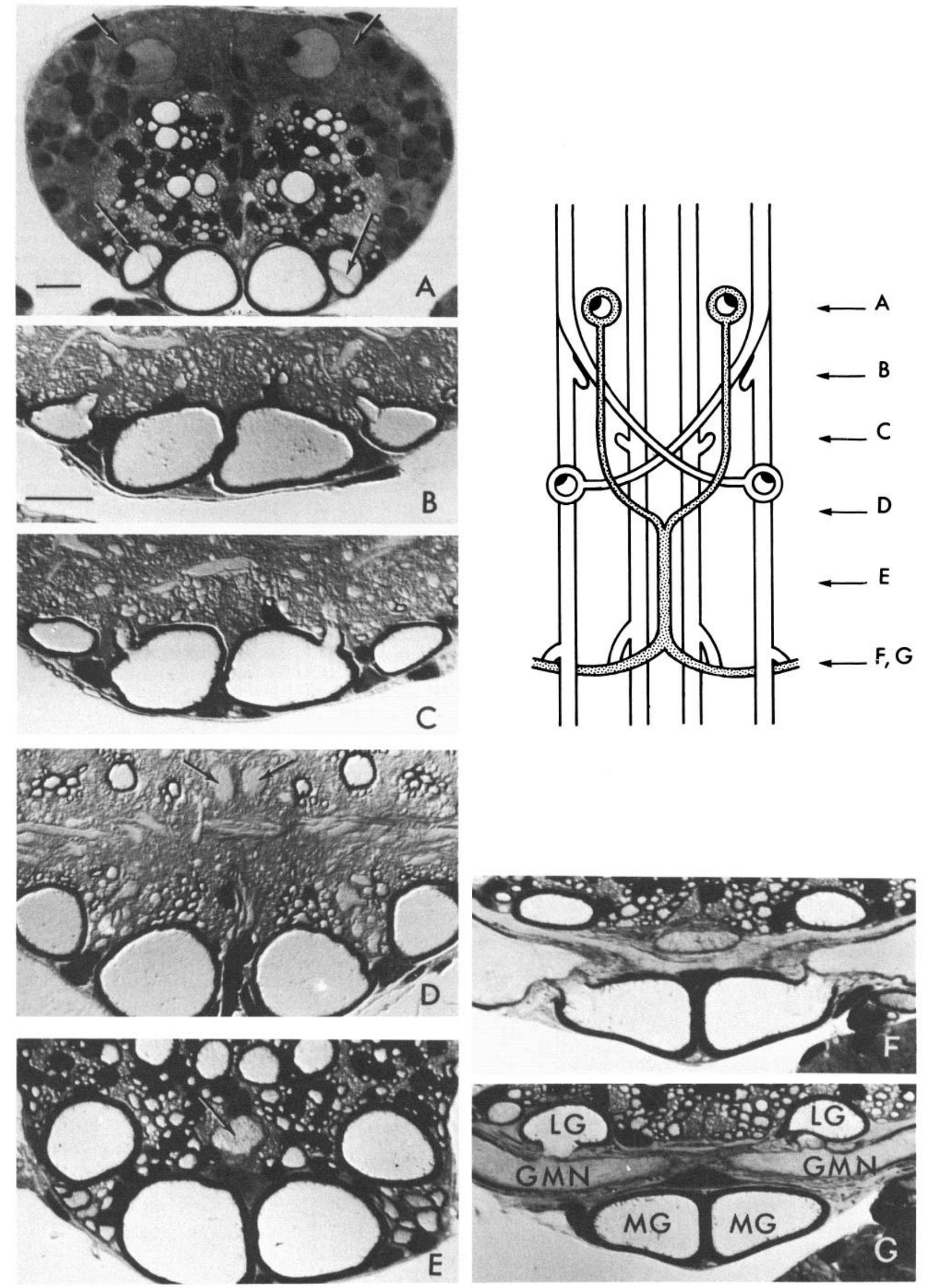

Figure 2. Giant neurons in late larva. Cross-sections of a typical ganglion in the first three abdominal segments are shown (ventral side up; micrographs are labeled in rostrocaudal order). The accompanying diagram corresponds to a ventral view of the relevant structures; GMNs are stippled; interneurons are clear. We have not traced the lateral giant (LG) axons to their 
Connectivity. The structure of the giant fibers in the fourth root region of the 2nd and 3rd abdominal ganglia of one embryonal (5 days before hatching) and one 1st stage larvae were examined at the EM level. For the analyses, we took micrographs of every fifth section of $0.1 \mu \mathrm{m}$ thickness and, when necessary, every section. All of the 8 GMNs examined in the 2 embryonal and 21 st stage ganglia had an extra process ipsilateral to the cell body (Fig. 4). Two of them made an anomalous contralateral contact. Both were MG-GMN connections in the 3rd abdominal ganglia, 1 in an embryo and 1 in a 1st stage larva. No unusual LG-GMN contacts were observed, and no anomalous contacts were found in the 2nd ganglia. Only $20 \%$ of the GMNs in 13-day or older larvae had an extra contralateral process as judged by LM. No anomalous contacts were observed in 2nd ganglia, and only MG-GMN anomalous contacts were observed, totaling $11 \%$ in the $3 \mathrm{rd}$ ganglia. The statistical significance of this excess in the number of contralateral connections in young larvae is, however, low due to the small number of these ganglia analyzed ( $p=0.091$ for pooled 2nd and 3rd ganglia; $p=0.074$ for 3rd ganglion only).

Fourth abdominal ganglion. As in crayfish (Mittenthal and Wine, 1973), the 4th abdominal ganglion of the adult prawn does not have LG-GMN contacts, while such contacts are present in the larval prawn (Fig. $3 B$ ). An additional feature in the 4th ganglion of the larval prawn is a prominent contact between left and right LGs in the motor root region (Fig. $3 B$ ). This connection is not present in adults. The early connection is mediated by a robust branch of the same collateral that gives rise to the LG-GMN connection.

\section{Spontaneous anomalies}

During the course of our studies, we encountered a variety of anatomical anomalies affecting the normal number or the trajectories of identified axons. Most of the animals analyzed for spontaneous anomalies had suffered microlesions in other abdominal ganglia. However, we classified them as spontaneous since they did not involve the irradiated cells. From the nature of these anomalies and the fact that they were observed in unirradiated ganglia, we believe that most had originated earlier in development, before the time of irradiation. The observations are based on analysis of serial sections of approximately 340 abdominal ganglia. Unless otherwise specified, the anomalies were observed in unirradiated ganglia.

Supernumerary axons. Although our observations usually extended over several abdominal segments, we have not traced axons completely back to their cell bodies, and the patterns observed might be the result of extra neurons or of extra branching of neurites within the neuropil, outside of the region investigated.

Ten lateral giant duplications were observed (Fig. 5, $C$, $E$, and $F$ ). Supernumerary axons were identified as LGs, by virtue of their characteristic size, lateral position in the dorsal region of the cord, and contacts. However, in some instances, the GMN on the side of the duplication was contacted by only 1 of the LGs on that side. It was also common that 1 of the duplicated LGs exhibited other anomalies, such as a shorter length or a partial displacement from its normal trajectory. Six duplications were observed in 175 unirradiated ganglia. Two of these ganglia had duplications in both sides. Three single duplications were located in 60 ganglia that had suffered a lesion removing a GMN. Given the low frequency of duplications, it is unlikely that the coincidence of these anomalies on both sides of 2 ganglia was due to chance alone $(p=0.002)$. No correlation was observed in the appearance of extra lateral fibers in different segmental ganglia of the same animal. A duplication also was found on the left side of an irradiated ganglion where the LG of the opposite side was removed. This case was among 39 ganglia in which at least $1 \mathrm{LG}$ was deleted.

In one case, a LG bifurcated repeatedly inside of its myelin sheath (Fig. $5 D$ ). The bifurcations occurred within the ganglion in which the cell body was located. Two of the axons reached the next anterior ganglion, where their LG and GMN targets had been removed. Neither axon made an anomalous contact. They tapered off, ending in the place where a LG usually terminates when lacking a LG target (see "Induced anomalies"). In another case, a lateral giant axon grew beyond the ganglion where it usually ends, extending over almost two segments, in the presence of its normal target. It terminated before the fourth roots and thus did not make contact with either the GMN or the LG of the distant segment. In 1 abdominal ganglion, there were three axons which could be identified as belonging to motor giants due to their size, configuration, and contacts (Fig. 5, $A$ and $B$ ).

Unusual trajectories. In 14 ganglia, there was an unusual topological configuration involving the medial giant and the motor giant on one side of the ganglion next to the fourth roots (Fig. $5 G$ ). In four of the six animals where this anomaly was observed, it was found in 3 ganglia. In roughly half of the cases, the displaced $\mathrm{MG}$ did not make contact with the GMN.

In 1 ganglion, the neurites of both GMNs followed very unusual trajectories while maintaining approximate bilateral symmetry (Fig. 6). The GMN axons ascended in the neuropil by following a path that brought them close

contralateral somata, but the position of the cell bodies was determined through lesion experiments. The horizontal arrows indicate the approximate level of the correspondingly labeled micrographs. A, The GMN cell bodies (short arrows) are located on the rostral end of the ganglion. Notice their clear nuclei and prominent nucleoli. The LG fibers have a septum (long arrows) which separates LG elements originating in different abdominal ganglia. The septum extends roughly two-thirds of a ganglion length. Each giant interneuron has two short collaterals per abdominal segment. The more rostral ones, at positions $B$ and $C$, are smaller and touch unidentified neurites. $D$, GMN neurites (arrows) in their dorsocaudal travel, a few micrometers before meeting on the midplane. $E$, Fused GMN axons (arrow) parallel to the LGs and MGs on the dorsal side of the ganglion. $F$ and $G$, The fused GMN axons split again, leaving the CNS to innervate the flexor muscles. In this region, they are contacted by the caudal collaterals of the giant interneurons. Notice the interruption in the myelination of the interneurons around the collaterals (see also $B$ and $C$ ). The bars correspond to $10 \mu \mathrm{m}$; the $b a r$ in $B$ applies to the remaining micrographs. 

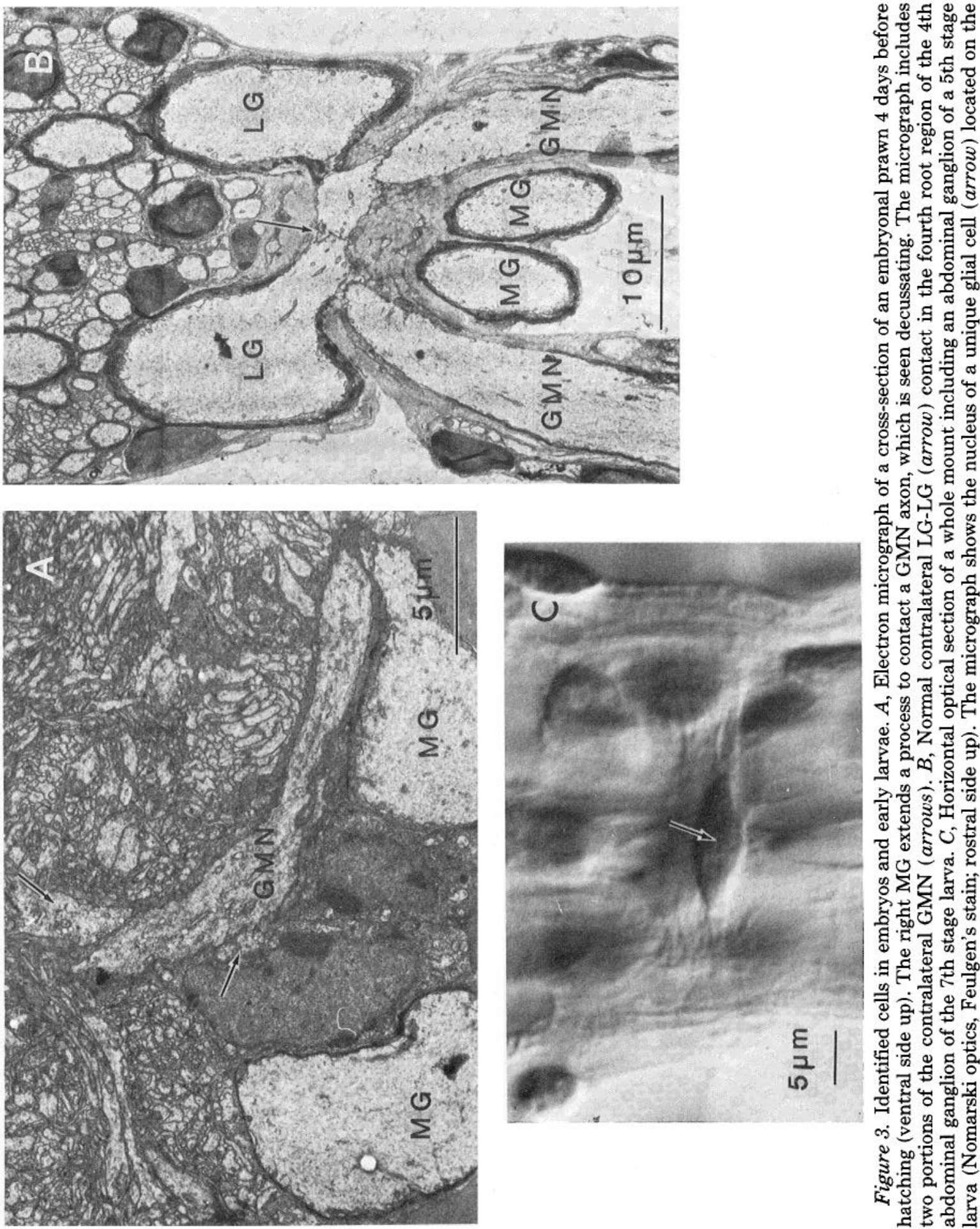

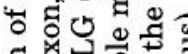
동 50.

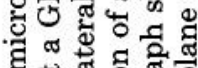

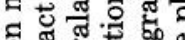
년 ठัญ ठำ 도유.륭

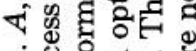

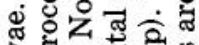
สี ส

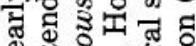

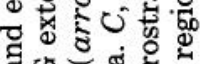

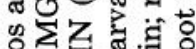

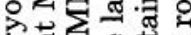
范心 द्व 虽 正

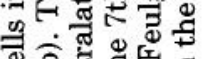

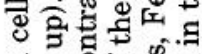

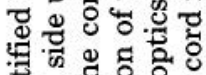

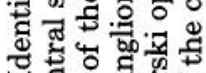

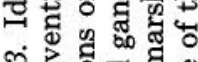
๗

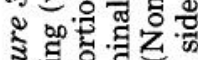

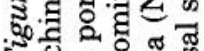

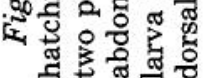



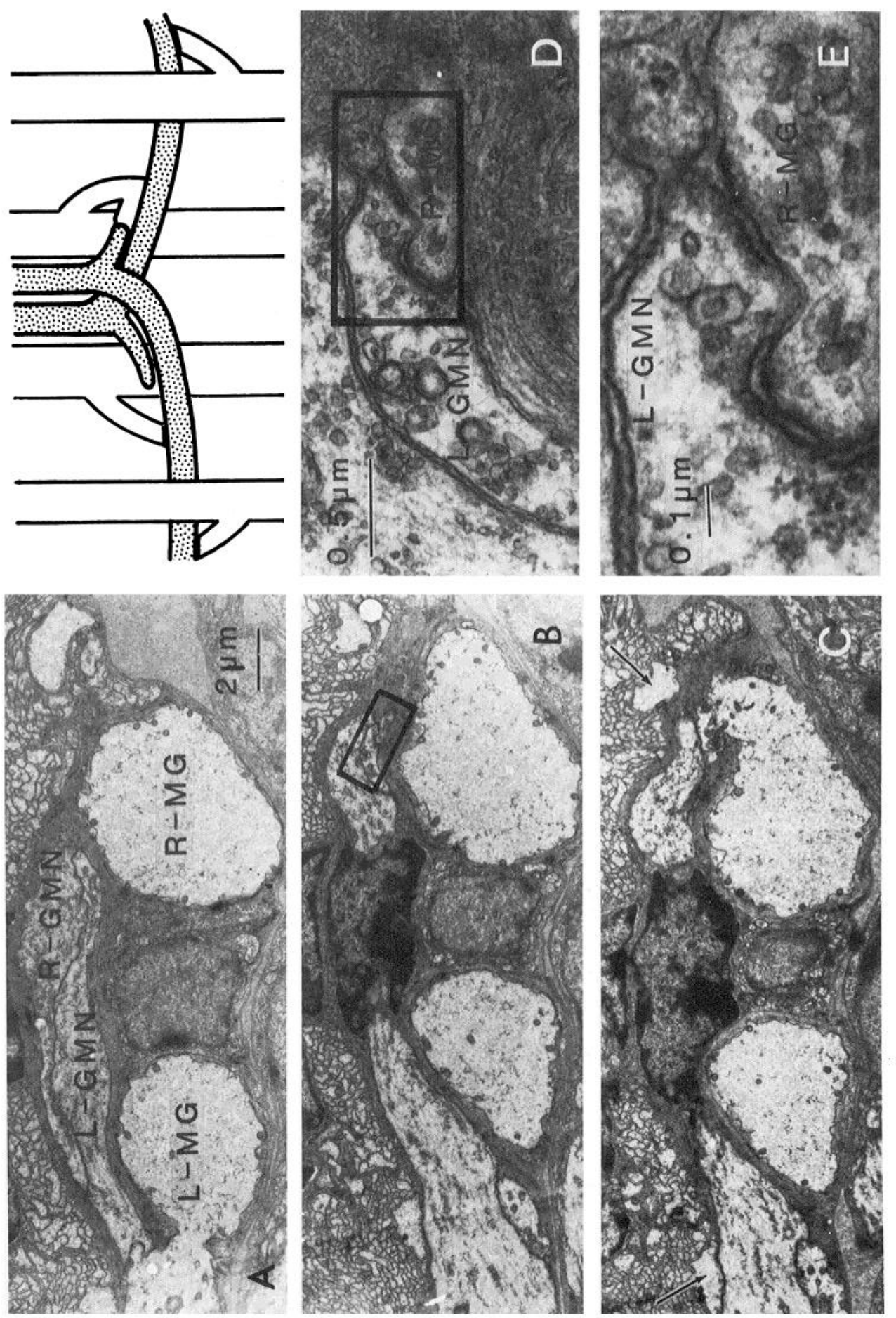

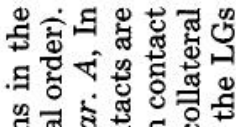

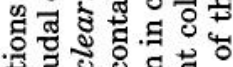

䒕 ๘

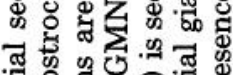

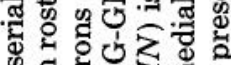

屯.

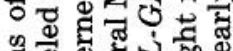

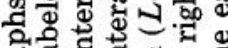

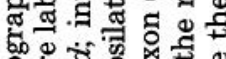

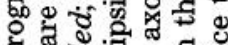

ปี

중

융 Ð

ब. क वृ

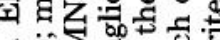

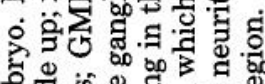

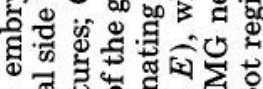

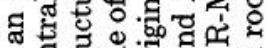

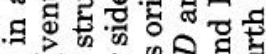

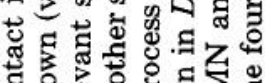

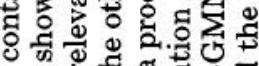

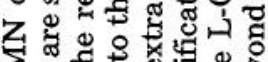
Z

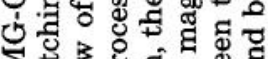

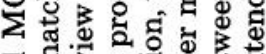
สี

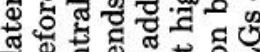
สై

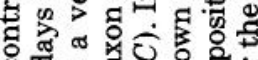
ठํㅇ

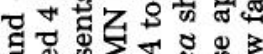

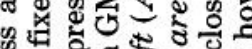

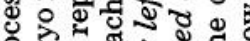
ة.

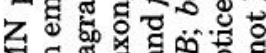

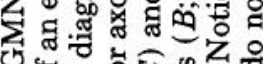
एँ 产 ชิ

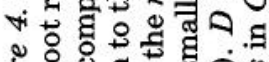
논

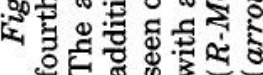



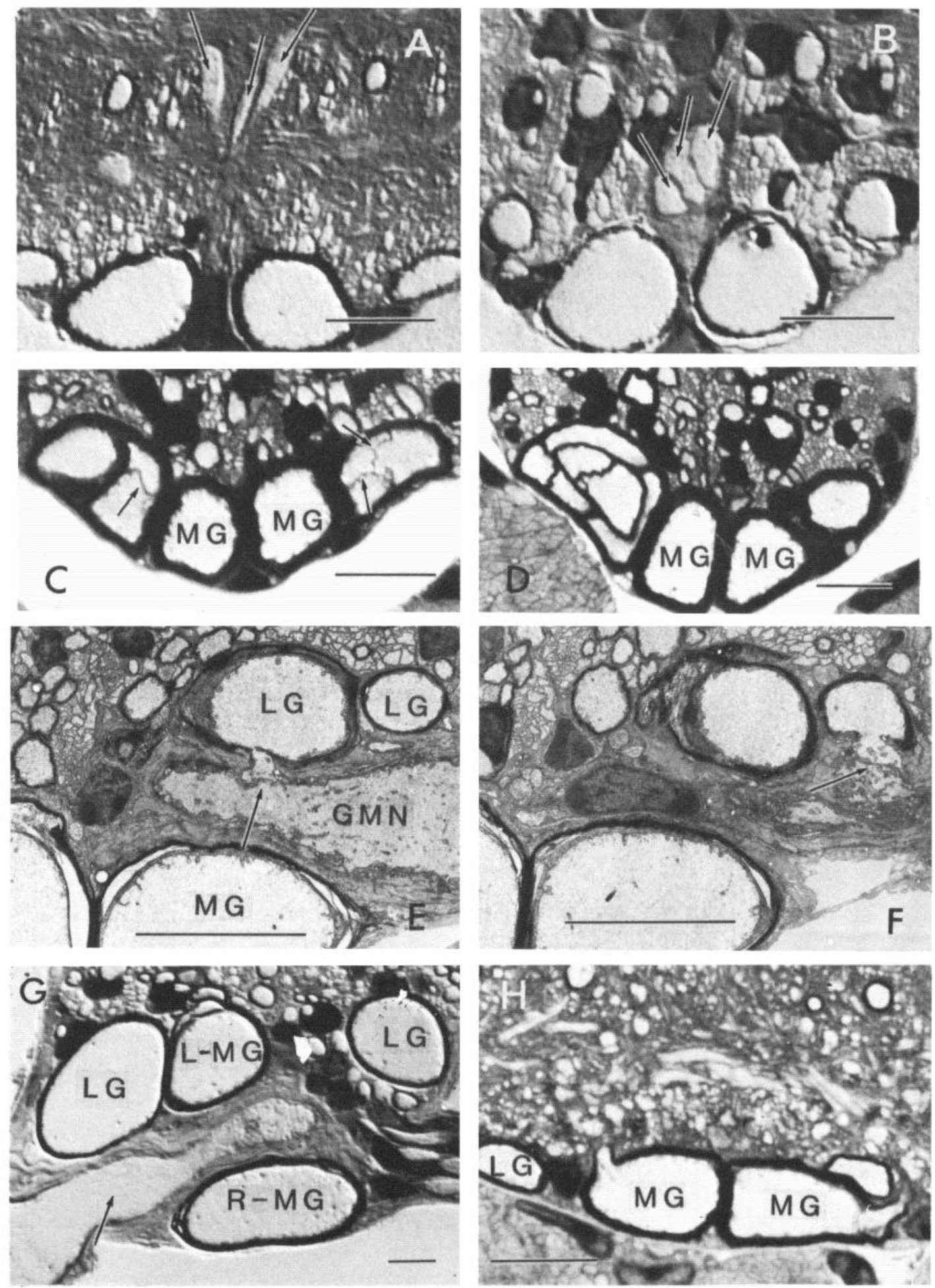

Figure 5. Supernumerary axons and topological anomalies. $A$ and $B$, Cross-sections of an abdominal ganglion with three GMN axons (ventral side up). $A$, The three neurites (arrows) in their travel toward the dorsal side of the ganglion. $B$, The three axons (arrows) are side by side, close to their exit through the fourth roots. $C$ to $F$, Cross-sections of abdominal ganglia having supernumerary LG axons. $C$, Two pairs of LG elements originated in this ganglion. The third pair of LG fibers seen in this section originated in the next caudal ganglion and ended normally at the rostral end of the one depicted. One of the LGs on the left is completely ensheathed with myelin; the other two share the sheath and are separated by a septum (arrow). The three LG elements on the right are separated by septa (arrows). D, In this ganglion, the left LG branched repeatedly. One small and six large axons are seen in this section. $E$ and $F$, Electron micrographs of the fourth root region of a ganglion with two right LG axons, both of which contact the GMN (arrows). $G$ and $H$, Cross-sections of abdominal ganglia illustrating the two topological anomalies described in the text. $G$, The left GMN axon (arrow) leaves the cord dorsally with respect to the left MG ( $L-M G$ ), which is ventrally displaced. $H$, The right LG is displaced and appears to be trapped by the collateral of the MG. The left side shows the normal configuration. The bars represent $10 \mu \mathrm{m}$. 


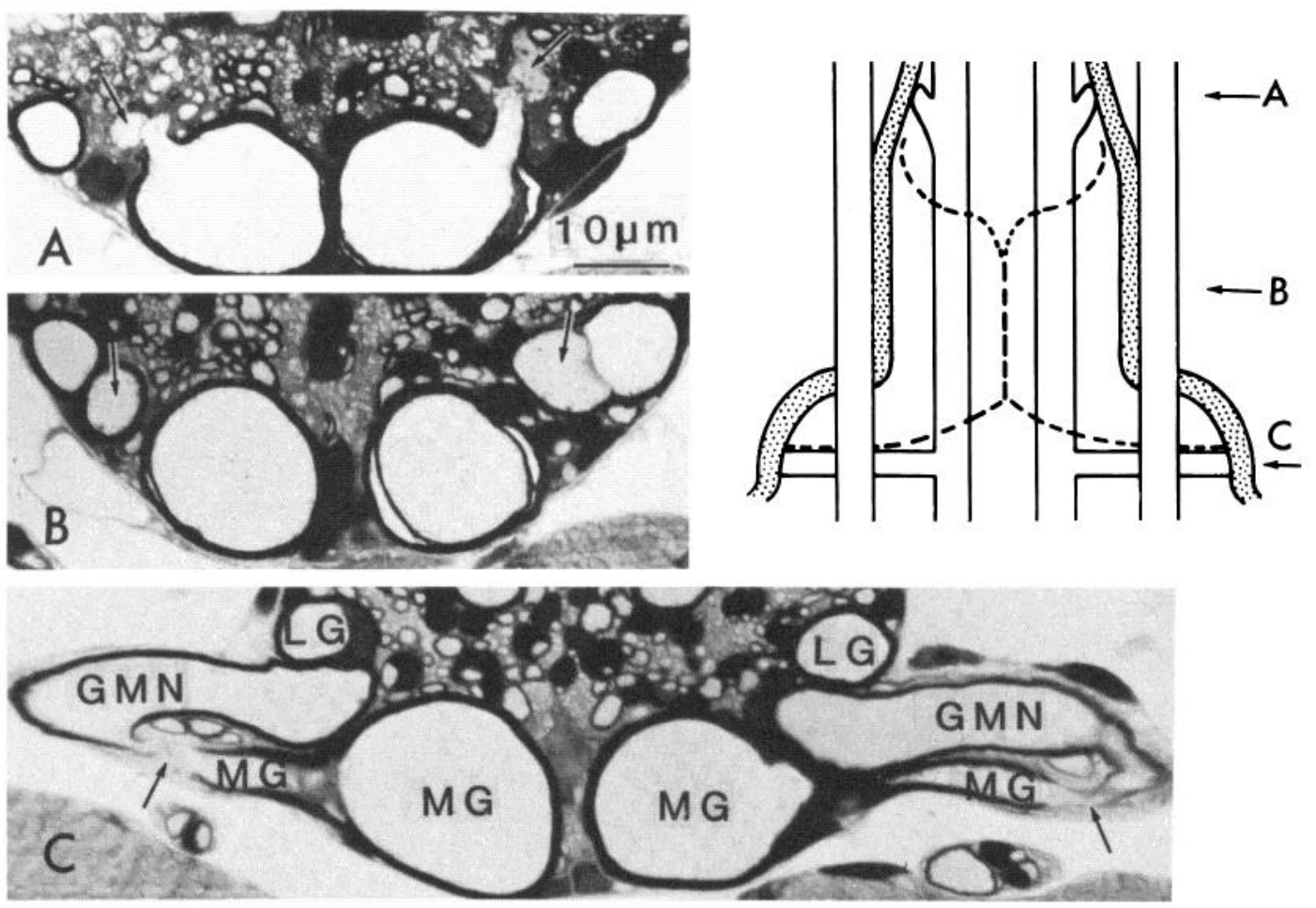

Figure 6. Unusual trajectory of GMNs. Cross-sections of abdominal ganglion are shown (ventral side up; light micrographs are labeled in rostrocaudal order). The accompanying diagram corresponds to a ventral view of the relevant structures. The horizontal arrows indicate the approximate level of the correspondingly labeled micrographs. Interneurons are clear; GMNs are stippled. The dashed lines represent the normal GMN trajectory (see Fig. 1 for illustration of normal morphology). The GMN neurites $(A$, arrows) travel through the mediolateral region of the ganglion, instead of the usual central location, and are contacted by the more central of the MG collaterals. The right motor axon $(B$, arrows) is seen in close contact with the LG. A similar contact also occurs on the left (not illustrated); in this figure, the left LG and GMN (B, arrows) are separated by myelin. Both LGs lack their normal collateral in the fourth root region. $C$, The GMNs receive the normal contact from the MGs in the fourth root region (arrows).

to the MG and LG of their respective sides well before the usual fourth root region.

In 7 ganglia, there was a displacement of the LG from its usual lateral position toward the midplane of the ganglion (Fig. $5 \mathrm{H}$ ). This displacement did not occur over the entire LG trajectory but was only seen in a restricted region of the ganglion. In 6 of the 7 cases, the point of maximum displacement was the same and could be recognized by a landmark present in both normal and anomalous ganglia. It consists of a short stout process of the MG which interrupts the myelin sheath of the giant fiber and contacts one or more unidentified fibers. In 5 of these 6 cases, the LG was displaced centrally with respect to the stout MG process in a configuration that reminds us of a finger pulling a stretched string. The LG in this region is myelinated, precluding any synaptic contact. Three of these 7 anomalies were observed among the 39 ganglia in which a LG soma had been irradiated close to the location of the MG collateral. The excess of anomalies in these ganglia is not likely due to chance $(p=0.03)$ and is probably a result of the lesion.

\section{Induced anomalies}

Small regions in selected abdominal ganglia containing a single giant soma were irradiated in order to study the effects of cell deletions on the connectivity of the remaining giant fibers. The microlesions were performed during the 1st larval stage within a day of hatching and killed cells with somata inside a sphere of $\sim 20 \mu \mathrm{m}$.

Effects of lesion. The first effects of a microlesion could be seen in the live animal, about 1 min after the irradiation began, as an opacity in the irradiated region (Fig. $7 B$ ). "Paling" of microirradiated parts of chromosomes was reported in experiments on cells grown in tissue culture while they were being observed under phase contrast optics (Uretz et al., 1954). In our experiments, the temperature of the water in the chamber containing the animal was kept low in order to anesthesize the animal. When the temperature of the water was allowed to ir srease, blood cells regained their normal movement, which was lost at low temperatures. A number of these circulating cells congregated, touching the ganglion close to the irradiated region.

Ganglia of animals which were fixed 2 days after a GMN had been irradiated showed a number of pyknotic nuclei in the irradiated region. We also have observed empty spaces at the site of irradiation (Fig. $7 C$ ). No cell was observed in the irradiated side with the relatively large nucleus and abundant cytoplasm that characterize the GMN soma, while the unirradiated motoneuron was easily recognizable. Axonal degeneration, as evidenced by the appearance of electron-dense inclusions, was seen in axons of irradiated GMNs 2 days after the lesion (Fig. $7, D$ and $E$ ). There is some variability in the time required for the axon to disappear completely, but, in 

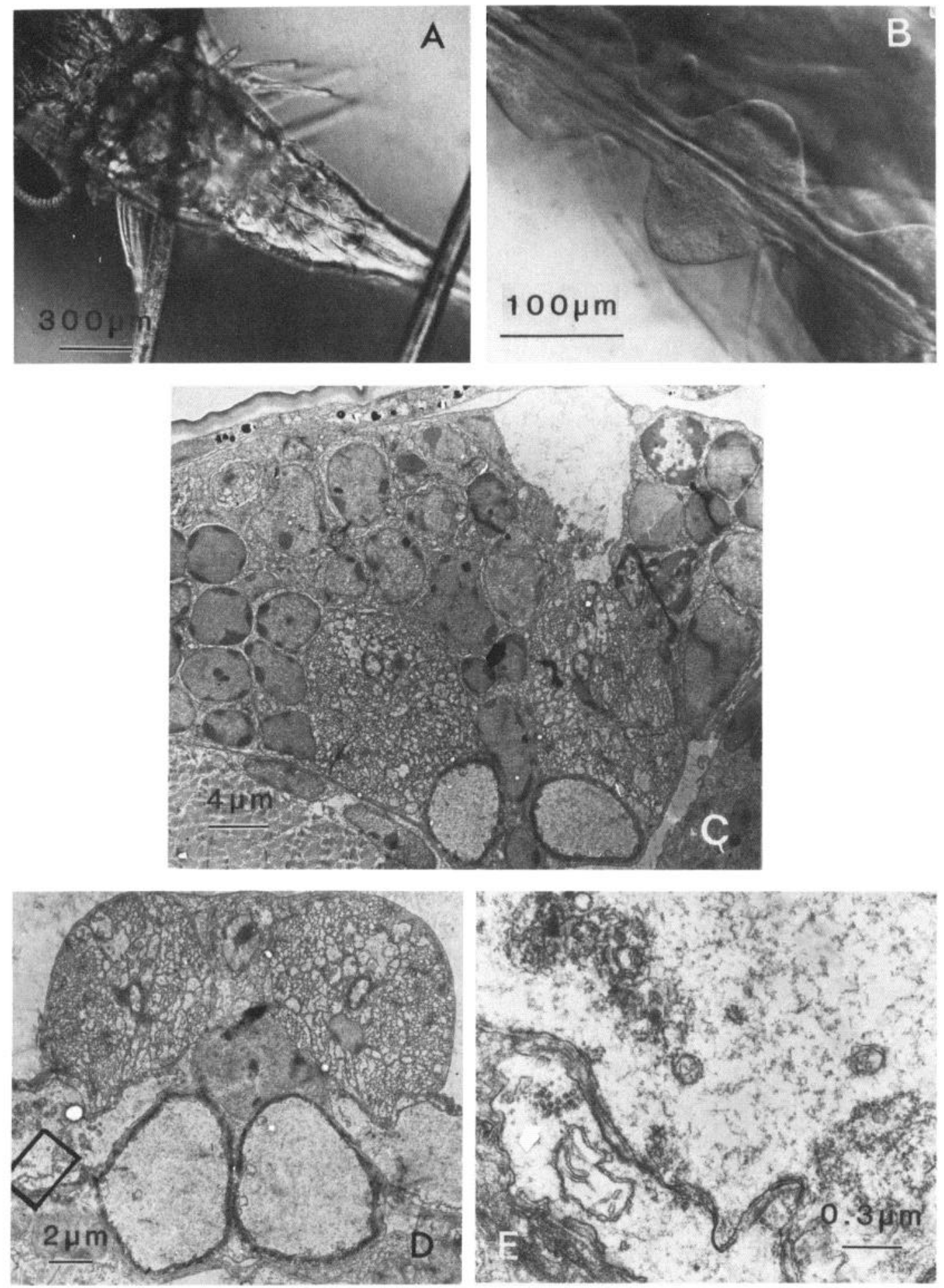

Figure 7. Lesion and its early effects. $A$, Larva is positioned in order to be irradiated, with its ventral side facing the objective (compound eyes on upper left; oblique illumination). The abdomen is pressed against a quartz coverslip, forced by two eyelashes acting as springs (oblique bands left of center and lower right). Notice the ventral cord with its ganglia running along the midline. $B$, Segment of abdominal cord (1st ganglion is in the upper left) a few minutes after irradiating a small region containing a GMN, left of the midline, close to the rostral end of the 2nd abdominal ganglion. A mark can be seen at the site of the lesion (oblique illumination). $C$ to $E$, Cross-sections showing the early effects of lesion on GMN ( 2 days after lesion; ventral side up). $C$, A hole is seen in the place where the GMN was presumed to be. Other cells are damaged also; see, for example, the pyknotic nucleus to the right of the empty space. The undamaged GMN does not appear in this picture due to the obliqueness of the cut. $D$ and $E$, The axon belonging to the GMN soma removed by the irradiation is still present but exhibits electron-dense inclusions, which seems to indicate that it was in the process of degenerating at the time of fixation. $E$ is a higher magnification view of the area framed in $D$. 
more than $90 \%$ of the ganglia observed, the GMN axon was not present after 10 days (Table II).

As a result of the deletion of a GMN cell body, there is a gradual shift in the position of the remaining GMN soma toward the midplane of the ganglion as if it were filling the space vacated by the disappearance of the irradiated cells (Fig. 8A). On the other hand, the path of the GMN neurite through the neuropil remained unchanged. This was strikingly illustrated in a case in which we inflicted an unusually heavy irradiation on one side of the ganglion. The remaining GMN cell body ended within the previously irradiated side in such a way that the cell body and axon were ipsilateral. Nevertheless, the GMN neurite entered the neuropil in the usual side, contralateral to the final position of the soma, and crossed over to the other side at a more posterior position (Fig. $8 B$ ). Since the neurite was present at the time of irradiation, the constancy of its trajectory deeper in the ganglion could be accounted for by the complex topological arrangement of the neuropil, which impedes displacements of an individual fiber without significantly altering its surroundings. This is in contrast to a less restricted arrangement of the cell bodies on the ganglion surface.

We limited our studies to experiments which remove GMNs and LGs, since their cell bodies are easily accessible to irradiation. When multiple lesions were made, they were done in the same session, with only a few minutes separating the irradiations. As a consequence of the lesions, identified cells in the giant fiber system lose one or more of their usual targets, while others are deprived of their normal afferent connections.

In order to delete the soma of a GMN, we used our knowledge of its precise location obtained from whole mounts of fixed ganglia. In view of our lack of knowledge of the location of the LG soma, we determined its approximate position by irradiating different places in the rear part of the ganglion and monitoring the survival of the identified axon. This was expected to be its general location, based on dye fillings of the LG cell body in the adult crayfish (Remler et al., 1968). As a result of this search, it was possible to delete the axon reproducibly by focusing the beam on a place in the ganglion which is defined in relation to the point at which the third root leaves the ganglion. The position of the LG cell body thus defined served equally well for both the 2 nd and 3rd abdominal ganglia.

For our standard methods of analysis with the light

\section{TABLE II}

Absence of a GMN axon following cell body irradiation

A summary of the observations on the presence or absence of axons belonging to GMNs whose somata had been microirradiated during the 1st larval stage is given. Ganglia were examined at different times after the lesion. In no case were we able to recognize a cell body with the normal size and position of GMN somata. The numerator stands for the number of missing motor giant axons; the denominator represents the number of treated hemiganglia.

\begin{tabular}{ccccc}
\hline \multicolumn{5}{c}{ Days after Lesion } \\
\hline $1-4$ & $5-8$ & $9-12$ & $13-20$ & $21-56$ \\
\hline $2 / 11$ & $6 / 11$ & $9 / 10$ & $23 / 24$ & $33 / 36$ \\
$(18 \%)$ & $(55 \%)$ & $(90 \%)$ & $(96 \%)$ & $(92 \%)$ \\
\hline
\end{tabular}

microscope, thin $(1-\mu \mathrm{II})$ sections were cut. For EM studies, ultrathin $(0.1-\mu \mathrm{m})$ serial sections were cut covering the fourth root region of the cord containing the collaterals of the LG and MG cells. In a late stage larva, this region extends for about 20 to $30 \mu \mathrm{m}$ along the longitudinal axis, requiring some 200 to 300 sections. Flanking regions were analyzed with the light microscope. Light and electron microscopic serial section analysis usually covered the 3 anterior ganglia.

Effects of lesions on connectivity of giant cells: $L G$ deletion. The observations were made at least 15 days after the microlesion when the axon of the unirradiated LG is already myelinated. At this time, the fiber of the irradiated cell had disappeared completely and a gap had formed in the segmental lateral giant system (Figs. 9 and 10). The proximal LG elements do not grow so as to close this gap. The ipsilateral LG unit in the next anterior segment shows no significant differences from the contralateral one. Such is not the case with the one originating in the next posterior segment, caudal to the irradiated one. This LG terminates closer to the posterior end of the ganglion than in controls. The shortening is equal to the distance over which the LG septum normally extends, which is about two-thirds of the length of the ganglion. The shorter LG ends at a place which, in normal ganglia, corresponds to the posterior limit of the septum. At this position, there is an opening in the myelin sheath that envelops the normal giant axon, permitting contact with the anterior segmental element and the exit of a short collateral belonging to the posterior unit. The normal collateral contacts a few unidentified fibers, including presumably non-giant flexor motoneurons (Kennedy et al., 1969; Krasne and Stirling, 1972). The site can be recognized in control and experimental ganglia by the fasciculation of fibers reaching toward the LG and by the dark toluidine blue staining of the surround.

We have verified through analysis of serial electron micrographs that the shorter LG element does, in fact, end in this region, contacting a few unidentified neurons. No fibers, not even very thin ones, were observed extending forward to contact the next segmental element or other cells beyond the defined region (Fig. 10, $D$ to $J$ ). Thus, the neuron has a conservative modification of structure, eliminating the portion of the axon that would have been in association with the deleted target.

T1_2 short LG made no unusual contacts in the fourth root region, and no new connections or collateral sprouting of giant interneurons were seen in LM analyses of the fourth root region in 17 ganglia that were missing one of the two LG axons as a result of the irradiation of its cell body, which is located in the next posterior ganglion. Ten of these microlesions were inflicted in the 2nd and 7 in the 3 rd abdominal ganglia. No anomalies were found in the 5 ganglia in which both $\mathrm{I}$, ss had been removed other than the absence of the lateral giant axons.

GMN deletion. In about a third of the ganglia analyzed to investigate the changes of connectivity following the removal of a GMN (Fig. 11), the study was done at the EM level. This was necessary to verify the complete disappearance of the GMN axon and is of particular importance since we are dealing with an animal belonging to a taxonomic order in which adult motor and interneu- 

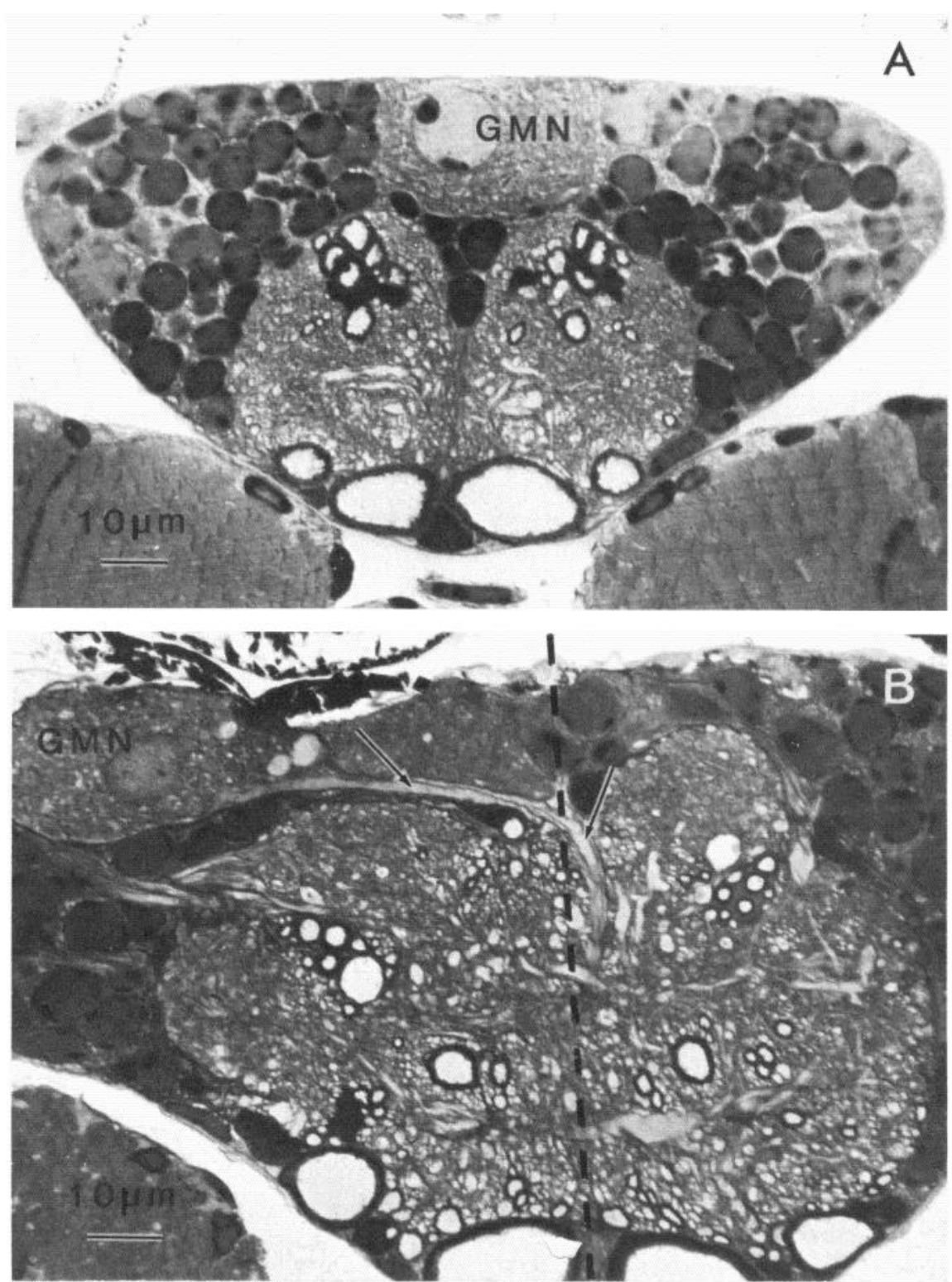

Figure 8. Displacement of undamaged cell bodies. Light micrographs of crosssections showing the late effects of the removal of a GMN on the position of the soma of the contralateral motor giant (ventral side up) are presented. $A$, The position of the remaining GMN cell body is usually shifted from its normal lateral position toward the center. $B$, A particularly heavy irradiation was inflicted on the left side, killing many cells. Cell bodies from the right, including the GMN, have migrated to the vacated region. Nevertheless, their neurites enter the neuropil in the normal place, on the same side where their cell bodies were originally located. Arrows indicate a fascicle, including the GMN neurite, crossing from left to right. The dashed line indicates the approximate position of the midplane. The obliqueness of this cut contributes to the asymmetry of the micrograph.

ron axons can be amazingly refractory to degeneration. In addition, we wanted to be certain that we could find all possible anomalies in the connectivity between the remaining neurons.

We first established that the microbeam is able to delete a GMN axon as a result of irradiation to its cell body. In addition, the 17 ganglia analyzed at the EM level did not show anomalous contacts between the deafferented giant interneurons and unidentified cells. It was, however, important for statistical reasons to increase the number of experiments by analyzing more ganglia with the light microscope, although this compromised the detail of the analyses. A comparison of the number of anomalous connections found by studying the lesioned ganglia at the LM or EM level shows that both methods gave similar frequencies for these events (Table III).

The most common result of the lesion is a minimal remodeling of the interneurons: the short collaterals that 


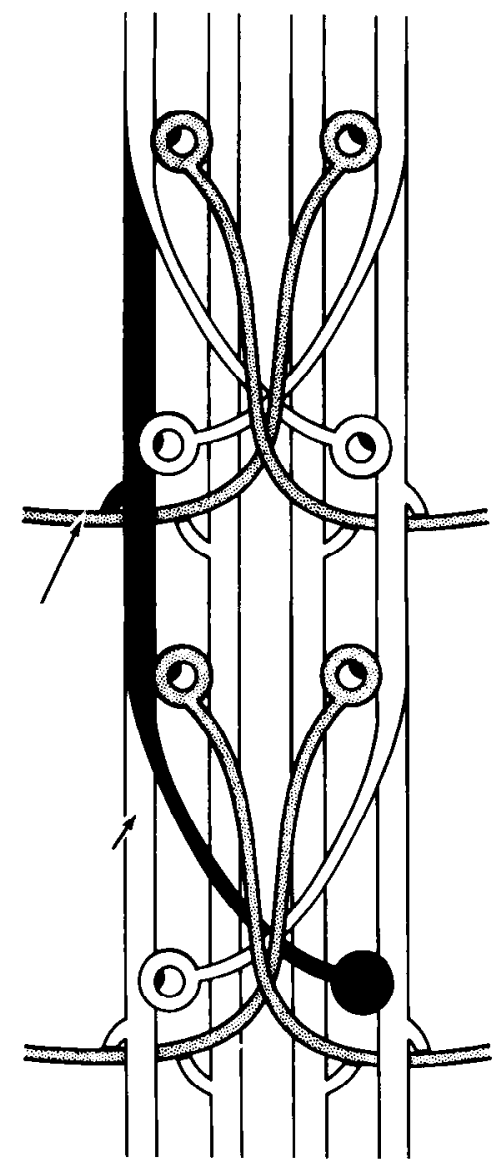

Figure 9. Removal of LG. When a LG is deleted (black cell), a LG (short arrow) loses a target, and a GMN (long arrow) loses an afferent contact. GMNs are stippled and interneurons are clear.

were in contact with the deleted GMN are resorbed (Fig. $10 C)$. The opening in the myelin through which each collateral passed does not appear and the axons of the interneurons appear completely ensheathed.

Anomalous contacts. In animals analyzed 13 or more days after the deletion of a GMN, about a third of the affected ganglia exhibited anomalous connections involving neurons whose GMN target had been removed. With a few exceptions, which we describe below, these connections involved a giant fiber deprived of its normal target and the contralateral GMN, which remained undamaged (Table III). The neurites involved in the anomalous contacts can be described as a combination of two configurations. In the first, the medial or lateral giant interneuron sends a collateral which crosses over the midplane and contacts the axon of the remaining motoneuron before it leaves the CNS (Fig. 12, $A$ and $B$ ). In the second configuration, it is the GMN that sends a neurite over the midplane, contacting one or both contralateral interneurons (Fig. 12, $D$ to $G$ ). The latter configuration is the more common one. On two occasions, we observed an unusual contact between left and right LGs in the fourth root region of ganglia other than the $4 \mathrm{th}$, where this is a normal occurrence. The two collaterals participating in the abnormal contact were not symmetrical, as is the case in the contralateral contact seen in undamaged 4th ganglia (Fig. $3 B$ ), but differed in shape and size (Fig. 12,
$H$ to $K$ ). No anomalies were seen in 26 irradiated ganglia in which no GMN was removed, including the 4 cases in which the irradiated GMNs survived.

In one case, we observed a contact between the $\mathrm{MG}$ and the LG of the side where the GMN had been removed. This anomaly, which was mediated by a very thin and short process, was in addition to a more prominent anomalous connection between contralateral MG and GMN. We have never observed connections between the giant interneurons and other axons in the fourth root region, even when both GMNs were deleted. The lack of such anomalies is noteworthy in view of the close proximity of many other axons, including motoneurons different from the very large giants, which are presumably contacted by the second collateral of the interneurons inside of the ganglion proper.

The following conclusions are suggested by comparing the incidence of anomalous contralateral connections in ganglia that had not suffered the deletion of a GMN and the frequency of anomalies in ganglia in which a GMN had been deleted ("experimental ganglia") (see Table III). (1) Although control ganglia show anomalous connections, their frequency is at least 10 -fold lower than the frequency of anomalies in experimental ganglia. (2) Anomalous contralateral LG-GMN contacts have been observed only after the ipsilateral GMN axon had been deleted. (3) Only MGs have been observed forming anomalous contacts in control ganglia, but the frequency of such contacts was much higher in irradiated ganglia.

Effects of GMN deletions in different segmental ganglia. We compared the frequencies at which anomalous contralateral connections were induced in the 2nd and 3rd abdominal ganglia, which had suffered the deletion of only 1 GMN and no other giant neuron (Table III). Anomalous connections were found more frequently in the 3rd ganglion, and although the samples are not large, the difference is significant.

Simultaneous LG and GMN lesions. Second abdominal ganglia in which ipsilateral GMN and LG were deleted (Fig. 13) showed anomalies at a higher frequency than those in which only the GMN had been removed. We observed an increase in the number of contralateral LG-GMN contacts, as compared with ganglia in which only the normal GMN target had been removed; however, this result could be due to chance alone $(p=0.26)$. Surprisingly, there was an increase in the number of contralateral MG-GMN contacts in the double lesion experiments, which is probably not due to chance. This excess could be due to nonspecific or unknown specific effects caused by some generalized damage to the ganglion.

In the ganglion having only one anomalous LG-GMN contact, the interneuron also overgrew, reaching from the 3 rd to the 1st ganglion, closing the gap left by the removed lateral element. The LG which extended beyond its normal termination contacted the ipsilateral GMN of the 1st ganglion. The case is interesting, since it indicates that a LG can recognize a GMN as its target, even when it belongs to a ganglion which it normally does not reach.

We also have analyzed the synaptic region of 4 ganglia in which a $L G$ axon had been deleted and the remaining LG axon had been deprived of its GMN target. This configuration was produced by irradiation of a LG soma 

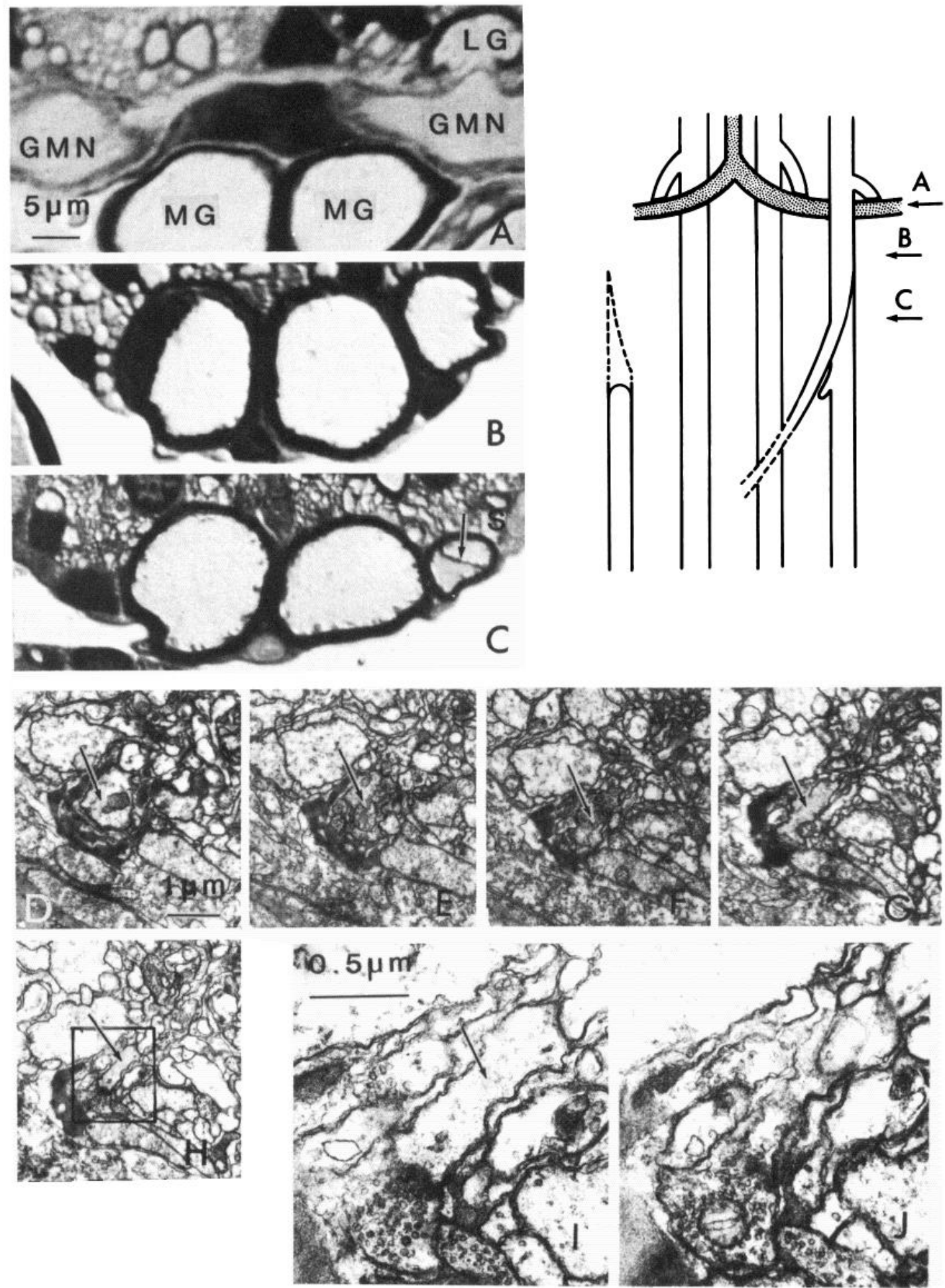

Figure 10. Effects of the removal of a LG. Light ( $A$ to $C$ ) and electron ( $D$ to $J$ ) micrographs of cross-sections illustrating the effects of experiments in which a LG was removed are shown (ventral side up; micrographs are labeled in rostrocaudal order). The accompanying diagram represents a ventral view of the relevant structures; GMN axons are stippled; interneurons are clear. The horizontal arrows indicate the approximate level of the correspondingly labeled micrographs. $A$, No anomalous connections are observed in the fourth root region in which the GMN on the left had been deprived of its afferent LG collateral. $B$, The MG is the only giant myelinated axon on the left. $C$, The LG element caudal to the deleted unit is shorter than usual (dashed axon in diagram represents normal axon): no LG axon is seen on the left, while the usual two elements, separated by a septum (arrow), are seen on the right. $D$ to $\mathrm{J}$, Serial micrographs at the tip (arrow) of an undamaged LG element whose rostral LG target had been removed. $D$ to $H$ are at $\sim 0.3-\mu \mathrm{m}$ intervals; $I$ is a higher power view of the boxed area in $H$. $I$ and $J$ (separated by $\sim 0.1 \mu \mathrm{m}$ ) show what appears to be the end of the LG axon. 


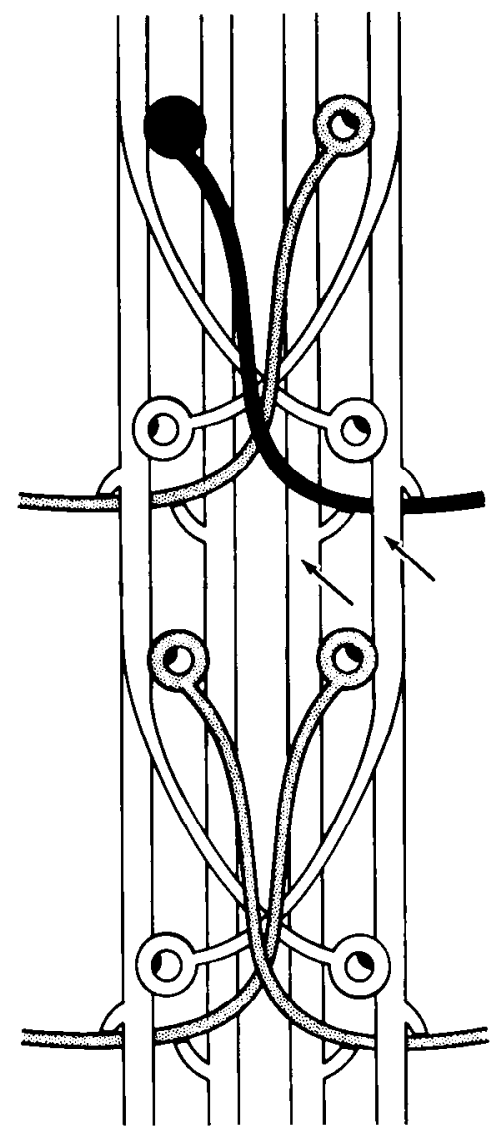

Figure 11. Removal of a GMN. When a GMN is deleted (black cell), a LG and a MG axon (arrows) lose a target. GMNs are stippled and interneurons are clear.

in the 3rd and the contralateral GMN in the 2nd abdominal ganglia, respectively. No anomalies were found in these experiments.

\section{Discussion}

Our observations show that, although the general plan of the ventral cord is established at the time of hatching and many adult features are present, the abdominal ganglia of the larval prawn undergo developmental changes of fundamental interest. These changes include: proliferation and differentiation of neurons and glia and changes in the connectivity between identified neurons.

The giant fibers of the prawn constitute a striking example of the constancy of structure that can be achieved by nervous systems. Two characteristics of the giant cells in the larval prawn permitted us to make precise observations: (1) they are easily identifiable cclls with axons of simple morphology and (2) contacts between them are mediated by identified collaterals situated in well defined regions of the CNS. Our studies, based on serial section microscopy, allowed us to determine if abnormalities or deletions of a neuron were correlated with changes in its relations with other cells.

Spontaneous anomalies. The characteristics of the anomalies which were classified as spontaneous lend support to two ideas: (1) identified axons of abnormal morphology do not lose their synaptic specificity. They can recognize their normal targets, or cells which are homologous to them, in regions which are not their usual target area. (2) The path taken by a growing axon during development cannot be deduced from the morphology of an axon. Extra fibers which are present only in earlier stages of development can be removed by editing, and an axon can be displaced from its original position. Topological barriers, such as other axons running in a direction perpendicular to the axon of interest, set a limit on such continuous changes.

Induced anomalies. The main emphasis of this work was in studying the consequences of microlesions which removed identified neurons (a GMN and/or a LG) during the larval development of the giant fiber system responsible for the tail flip response in Decapod crustacea. In our experiments, axons belonging to irradiated cell bodies disappeared within 10 days, in contrast to the slow degeneration of isolated adult invertebrate axons (Hoy, $1969,1973)$. The observed difference could be due to the means by which lesions are inflicted: in previous work, axons usually were separated completely from their somata by cutting or crushing a nerve. In our experiments, the cell body stays in contact with its axon. However, probably of more importance is the fact that our experiments were done on very young and immature animals, while the earlier work was done on adults.

We concentrated on the transneuronal effects of the deletions of identified neurons. Our observations showed that axons or collaterals are not rigidly specified by intrinsic properties but that their morphology can be modified as a consequence of changes in the cellular environment. The most common result of removing a target GMN was the absence of the collaterals of the MG and LG neurons deprived of their targets. When one segmental element of the LG system was removed, the chain had a gap which was not filled by subsequent growth. The axon of the element immediately posterior to the deleted element was shorter than its contralateral homologue. The removal, or lack of development, was complete: the remaining axon or collateral ended where it contacted a target. In $30 \%$ of the ganglia where a GMN was killed and the structure was analyzed 21 or more days after irradiation, one or more anomalous connections were found. The removal of an identified interneuron-the LG-did not elicit sprouting of either the undamaged mirror image neuron or the contralateral MG, which had not suffered the loss of a target. Studies of the effects of the removal of a giant motoneuron do show that sprouting takes place in the periphery (Friedlander and Levinthal, 1980).

Our observations show a pattern in the anomalous connections following the removal of the normal GMN target of $L G$ and $M G$ fibers. The normal connections of the giant interneurons are on the ipsilateral GMN. In the absence of the normal target, we observe contralateral interneuron-GMN contacts, but no contacts are made on other axons. The restricted types of anomalies observed support the notion of a hierarchical order in the rules governing the formation of central synapses, in which the correct matching of neuron types is more important than the preservation of laterality. Such rules would account for more macroscopic observations done on vertebrate 
TARIF III

Anomalous connections following removal of GMN

A summary of light (LM) and electron microscope (EM) observations, investigating the presence of anomalous connections in ganglia suffering the deletion of a GMN axon 13 or more days after irradiating a small region containing the GMN cell body, is given. The deleted axon was a target of the LG and MG interneurons involved in the anomalies. Only anomalous LG- and MG-GMN contacts are listed; other wrong connections were extremely rare (see text). The numerator represents the number of anomalies within the category, while the denominator stands for the maximum number which might have been observed if every remaining GMN axon exhibited the anomaly. Percentages are approximations of the fractions; SD is the unbiased estimate of the standard deviation of the binomial distribution associated with each fraction. Total anomalies were added from experiments deleting: (1) a single GMN in the 1st, 2nd, or 3rd abdominal ganglion; (2) a GMN and the ipsilateral LG in the 2nd ganglion; and (3) a GMN in the 2nd ganglion and the contralateral LG in the 3rd one (four larvae, no anomalies). Statistical significance of differences between groups b and $\mathrm{c}: p(c)=0.068 ; p(g)=0.071$ and groups $\mathrm{b}$ and $\mathrm{d}: p(c)=0.016$ (LG-GMN contacts only: $p=0.26$; MG-GMN contacts only: $p=0.009) ; p(g)=0.05$.

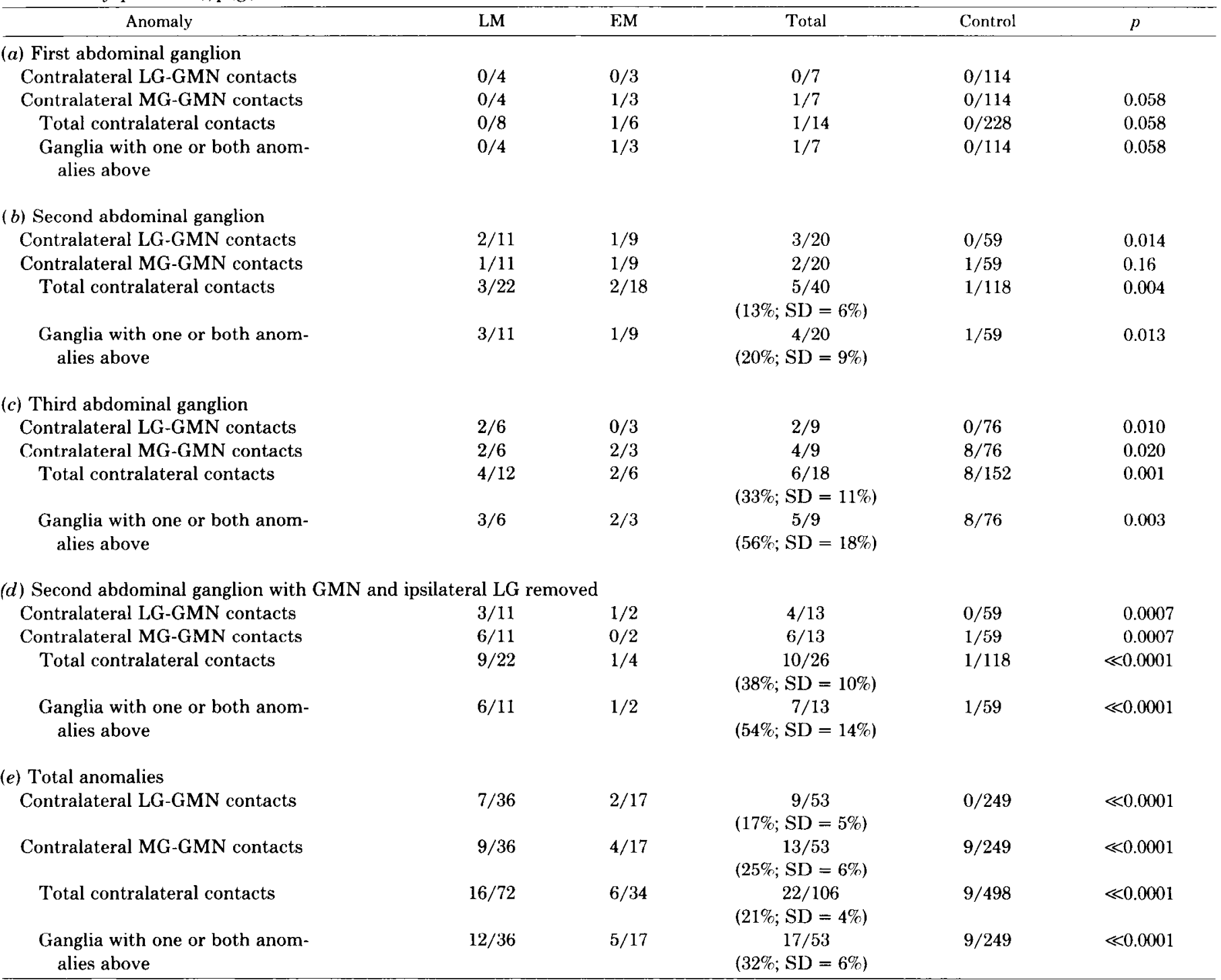

material (see Lund, 1978, p. 165): when one side of a brain is removed, axons which would have terminated there arborize in the corresponding regions and at the same levels in the remaining side.

Three different kinds of events may lead to the formation of the unusual connections: (1) maintenance of previously existing contacts which would have been removed during normal development, (2) de novo formation of contacts, and (3) slow degeneration of the irradiated GMN axon, followed by fusion of this process with the undamaged contralateral homologue. The last hy- pothesis seems the most unlikely, since the irradiated GMN usually degenerates within 10 days, while fusion of the GMNs in control 2nd and 3rd abdominal ganglia has not been observed in animals younger than 20 days.

Analysis of the normal connectivity at the time of irradiation lends support to the first hypothesis. EM observations in embryos and 1st stage larvae invariably showed the presence of an extra GMN neurite. Only some of these extra processes made anomalous connections, which were contralateral MG-GMN contacts. The frequency of anomalous contacts in young ganglia was 

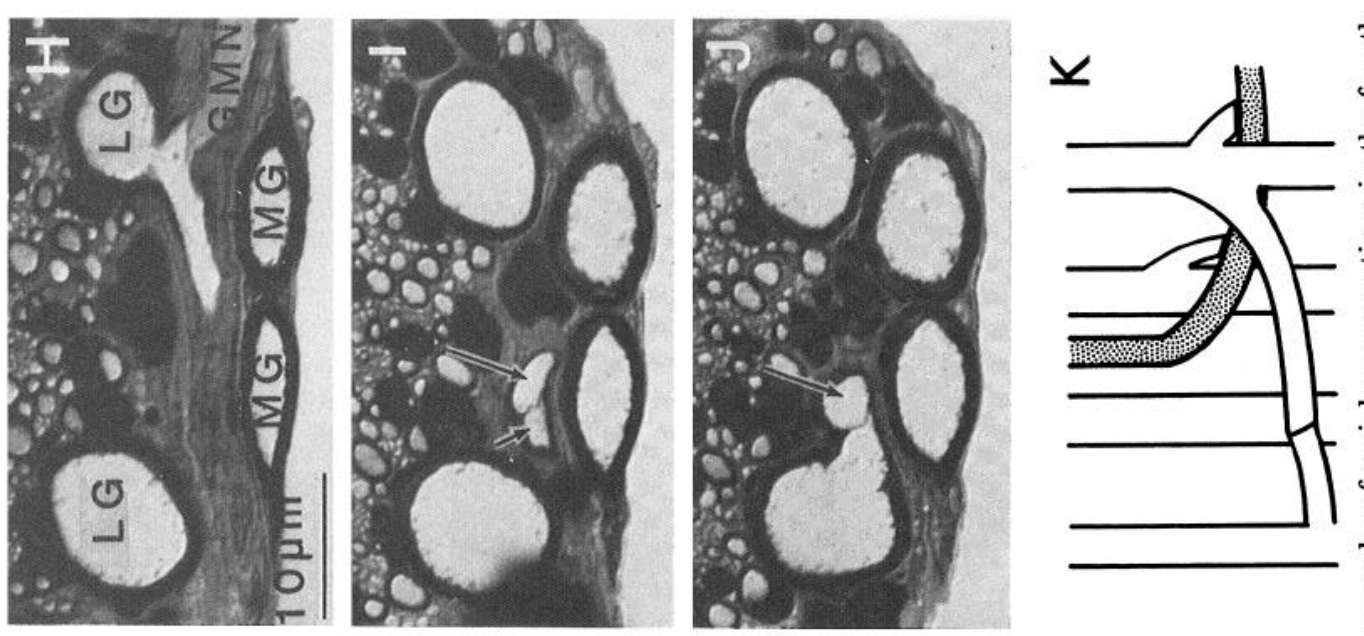

赵胥

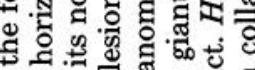
a 4 菏

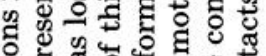

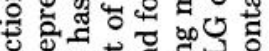

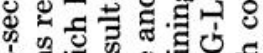

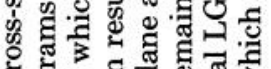

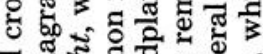

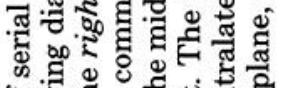

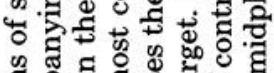
帘
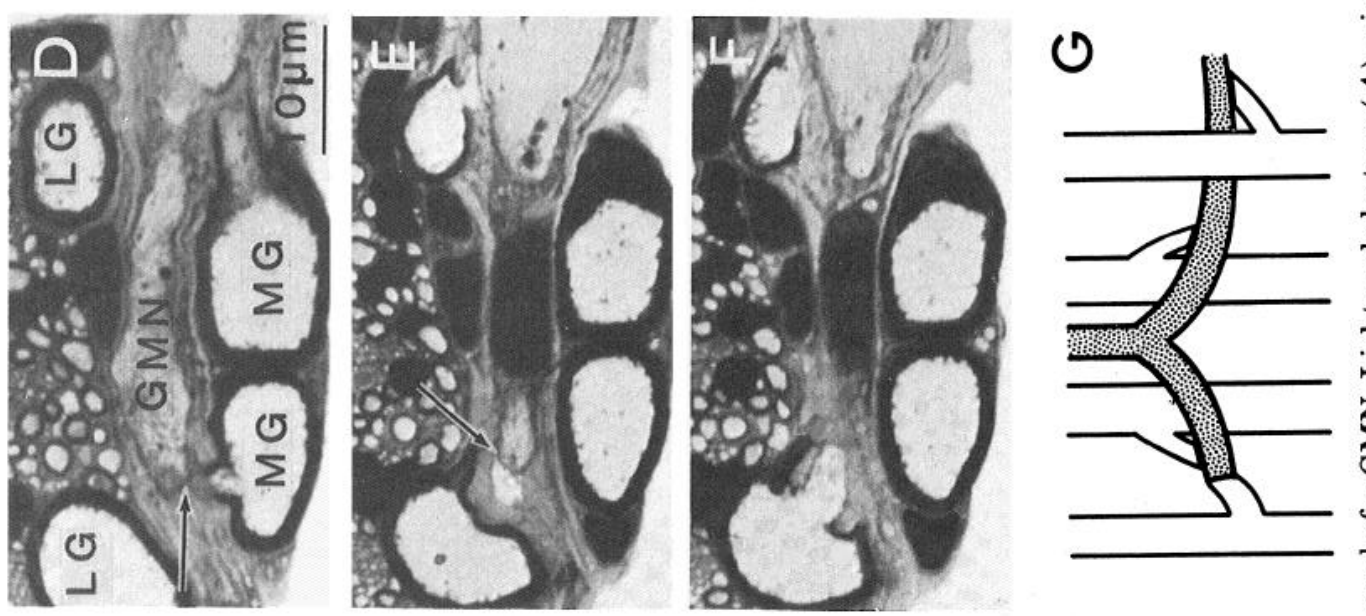

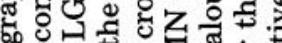

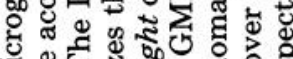
类. 窟 दे

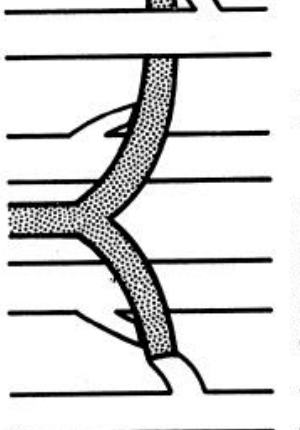
绾

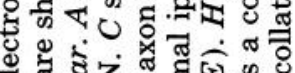

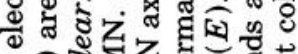

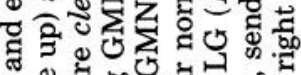

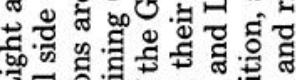

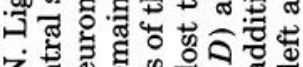
$\sum_{0}$ क ส

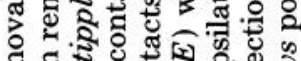
뒁
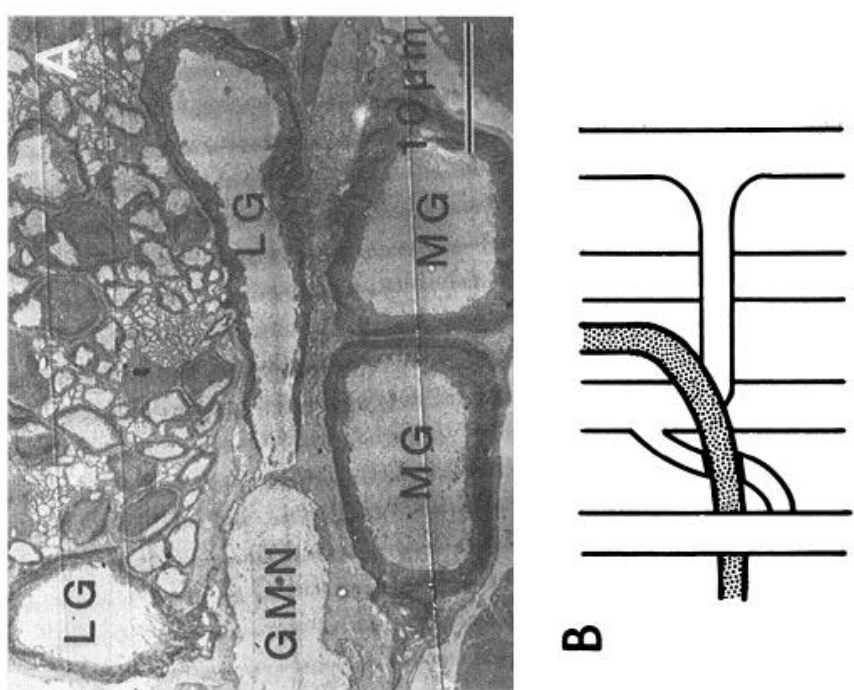

$\infty$

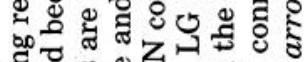

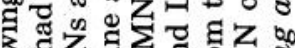

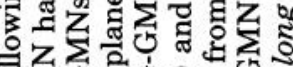

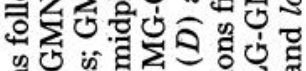

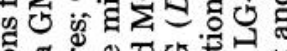

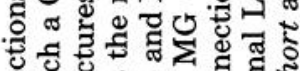
选

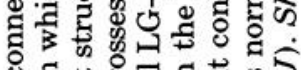

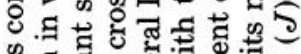

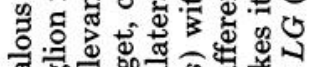

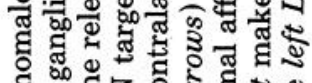

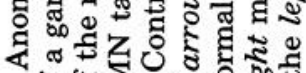
ง งิ่ 今.

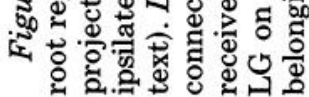




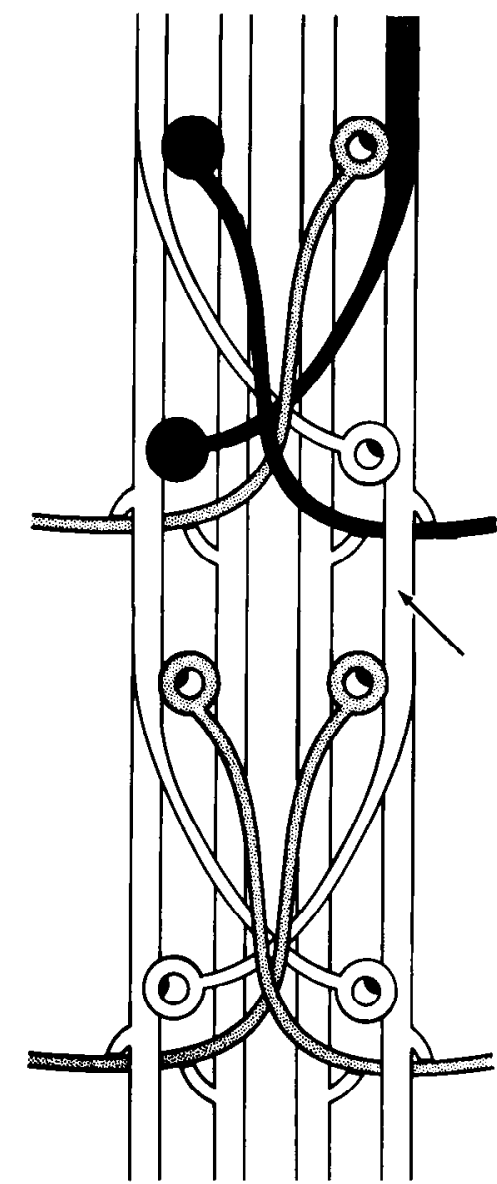

Figure 13. Double lesion. When ipsilateral LG and GMN are removed (black cells), a IG (arrow) loses its two most conspicuous targets. GMNs are stippled and interneurons are clear.

much higher than in older control ganglia and was similar to the one observed in ganglia suffering the deletion of a GMN. Although the small number of young ganglia analyzed does not allow us to make a strong quantitative statement, these observations lend support to the notion that an editing mechanism is involved in removing connections in normal development. On the basis of these observations, we suggest that the anomalous MG-GMN connections found after deleting a GMN were present at the time of the lesion; they were not removed since they constituted the only connection of the MG collateral that had been deprived of its normal ipsilateral GMN target. The data are insufficient to make a statement about the origin of the LG anomalies.

Conclusions. Several generalizations can be abstracted from the results of these studies on the development and plasticity of the giant fibers of the larval prawn. We believe that these conclusions are important for two reasons: (1) plastic phenomena were observed in one of the most rigid invertebrate systems and (2) they apply to identified collaterals of identified neurons. These generalizations can be summarized in four rules:

1. The stereotyped final contacts made by neurons in a normal animal are only a subset of the connections that would be allowed within a context different from the normal one. This is substantiated by the anomalous contacts made by the giant interneurons when deprived of their usual ipsilateral GMN target and by the collateral sprouting of a GMN into partially denervated muscles on the side of the animal that it normally does not innervate.

2. The types of anomalous contacts made by neurons in abnormal contexts are restricted. We base this on the fact that the anomalies observed in the CNS are of a few types: contralateral MG-GMN, LGGMN, and LG-LG connections, while other cells in the vicinity are not contacted by the giant motoneurons.

3. Developing neurons can have processes and connections that are not present in later life. This is based on the presence of extra GMN processes and their anomalous connections in embryos and young larval ganglia in the anterior ganglia and the LG-LG and LG-GMN contacts in the 4th ganglion of larvae, which are removed in later development.

4. A collateral without a target is not viable. This is supported by the results of experiments removing a GMN and those deleting a LG. In the occasions in which no anomalous connections were formed when deleting a GMN, the deprived MG collaterals were removed and the LG collaterals failed to develop. In experiments deleting a LG unit, the next posterior element was shorter than normal, ending precisely in the place where it usually makes contact with unidentified neurites.

We believe that the general conclusions summarizing our experiments proposed here are important in that they can provide specific suggestions as to the mechanisms which determine developmental processes. The first two statements above are consistent with a notion of hierarchical order in the organization of specific nerve connections. More explicitly, a target cell is better matched with one type of neuron, e.g., T1, than with another of a type which we designate T2. One obvious mechanism underlying such a "rule" is that surface recognition molecules on the target neuron match those on T1 neurons more effectively than those on T2 neurons. However, this notion would have to be supplemented by the idea that the formation of a successful contact limits the ability of a target cell to receive new or maintain previous contacts with other cells. Mechanisms in which trophic factors or electrical activity play central roles have been postulated to explain such elimination of synapses. One possible molecular event which could lead to this reduction would be an aggregation of the recognition molecules in both the neuron and the target cell.

Thus, if the usual, or correct, cell of type T1 is absent or arrives at the target late, then another cell of the same type can make a successful contact and saturate the $\mathrm{T} 1$ recognition molecules on the target cell. The presence of extra neurites in larvae then would be the result of observing a developing system at a time when neurons are still selecting their final targets among a pool of competent cells. We might assume that, at this early time, neurons can send out many neurites which do not establish "successful" contacts which are sufficiently strong to promote the aggregation of the recognition molecules, whereas, at a later time, a contact which is 
strong enough to promote aggregation will cause other neurites of the same type to fall away when the recognition molecules involved in the attachment were withdrawn into the first aggregated form. A hypothesis of this type could account for the reduction of synapses in a wide variety of systems by assuming that the availability of recognition molecules at the tip of a neurite is dependent on factors such as the distance of the tip from the cell body and the number of processes of the neuron.

\section{References}

Baylor, D. A., and J. G. Nicholls (1971) Patterns of regeneration between individual nerve cells in the central nervous system of the leech. Nature 232: 268-270.

Bowling, D., J. Nicholls, and I. Parnas (1978) Destruction of a single cell in the central nervous system of the leech as a means of analyzing its connections and functional role. J. Physiol. (Lond.) 282: 169-180.

Denburg, J. L., R. L. Seecof, and G. A. Horridge (1977) The path and rate of growth of regenerating motor neurons in the cockroach. Brain Res. 125: 213-226.

Edwards, J. S., and J. Palka (1973) Neural specificity as a game of cricket: Some rules for sensory regeneration in Acheta domesticus. In Developmental Neurobiology of Arthropods, D. Young, ed., pp. 131-146, Cambridge University Press, London.

Friedlander, D. R., and C. Levinthal (1979) Anomalous connections between identified neurons following microlesion in the larval prawn Macrobrachium rosenbergii. Soc. Neurosci. Abstr. 5: 245 .

Friedlander, D. R., and C. Levinthal (1980) Collateral sprouting of identified motoneuron following microlesion in the larval prawn Macrobrachium rosenbergii. Soc. Neurosci. Abstr. 6: 496.

Holmes, W. (1942) The giant myelinated nerve fibers of the prawn. Philos. 'Trans. K. Soc. Lond. (Biol.) 231: 293-311.

Hoy, R. R. (1969) Degeneration and regeneration in abdominal flexor motor neurons in the crayfish. J. Exp. Zool. 172: 219232.

Hoy, R. R. (1973) The curious nature of degeneration and regeneration in motor neurons and central connectives of the crayfish. In Developmental Neurobiology of Arthropods, D. Young, ed., pp. 203-232, Cambridge University Press, Iondon.

Hoy, R. R., G. D. Bittner, and D. Kennedy (1967) Regeneration in crustacean motoneurons: Evidence for axonal fusion. Science 156: 251-252.

Jacobson, M. (1978) Developmental Neurobiology, Ed. 2, Plenum Press, New York.

Jagger, J. (1967) Introduction to Research in Ultraviolet Photoradiology, Prentice-IIall, Englewood Cliffs, NJ.

Jansen, J. K. S., and J. G. Nicholls (1972) Regeneration and changes in synaptic connections between individual nerve cells in the central nervous system of the leech. Proc. Natl. Acad. Sci. U. S. A. 69: 636-639.

Jansen, J. K. S., K. J. Muller, and J. G. Nicholls (1974) Persistent modification of synaptic interactions between sensory and motor nerve cells following discrete lesions in the central nervous system of the leech. J. Physiol. (Lond.) 242: 289-305.

Johnson, G. E. (1924) Giant fibers in crustaceans with special reference to Cambarus and Palaemonetes. J. Comp. Neurol. 36: $323-373$

Kennedy, D., A. I. Selverston, and M. P. Remler (1969) Analysis of restricted neuronal networks. Science 164: 1488-1496.

Krasne, F. B., and Ch. A. Stirling (1972) Synapses of crayfish ganglia with special attention to afferent and efferent connections of the lateral giant fibers. Z. Zellforsch. Mikrosk. Anat. 127: 526-544.
Leuchtenberger, C. (1958) Quantitative determination of DNA in cells by Feulgen microspectrophotometry. In General Cy. tochemical Methods, J. F. Danielli, ed., Vol. 1, pp. 219-278, Academic Press, New York.

Levinthal, C., E. Macagno, and C. Tountas (1976) Computer aided reconstruction from serial sections. Fed. Proc. 33: 23362340 .

Ling, S. W. (1962) Studies on the rearing of larvae and juveniles and culturing of adults of Macrobrachium rosenbergii (De Man). Indo-Pac. Fish. Counc. Curr. Affairs Bull. 35: 1-11.

Ling, S. W. (1967) Methods of rearing and culturing Macro brachium rosenbergii (De Man). FAO Exp. Paper 31: 1-11.

LoPresti, V., E. R. Macagno, and C. Levinthal (1973) Structure and development of neuronal connections in isogenic organisms: Cellular interactions in the development of the optic lamina of Daphnia. Proc. Natl. Acad. Sci. U. S. A. 71: 433437.

Lund, R. D. (1978) Development and Plasticity of the Brain Oxford University Press, New York.

Macagno, E. R. (1977) Abnormal synaptic connectivity following UV-induced cell death during Daphnia development. In Cell and Tissue Interactions, J. W. Lash and M. M. Burges, eds., pp. 293-309, Raven Press, New York.

Macagno, E. R. (1978) Mechanism for the formation of synaptic projections in the arthropod visual system. Nature 275: 318320.

Macagno, E. R. (1979) Cellular interactions and pattern formations in the development of the visual system of Daphnia magna (Crustacea, Branchiopoda). I. Interactions between embryonic retinular fibers and laminar neurons. Dev. Biol. 73: 206-238.

Macagno, E. R. (1980) Number and distribution of neurons in leech segmental ganglia. J. Comp. Neurol. 190: 283-302.

Macagno, E., and D. R. Friedlander (1976) Demonstration of a syncytium by the migration of horseradish peroxidase between neurons in the prawn, Macrobrachium rosenbergii. Soc. Neurosci. Abstr. 2: 174.

Macagno, E. R., C. Levinthal, and I. Sobel (1979) Three dimensional computer reconstruction of neurons and neuronal assemblies. Annu. Rev. Biophys. Bioeng. 8: 323-351.

Miller, J. P., and A. I. Selverston (1979) Rapid killing of single neurons by irradiation of intracellularly injected dye. Science 206: 702-704.

Mittenthal, .J. F., and J. J. Wine (1973) Connectivity patterns of crayfish giant interneurons. Visualization of synaptic regions with cobalt dye. Science 179: 182-184.

Muller, K. J., and S. Carbonetto (1979) The morphological and physiological properties of a regenerating synapse in the CNS of the leech. J. Comp. Neurol. 185: 485-516.

Murphey, R. K., and R. B. Levine (1980) Mechanisms responsible for changes observed in response properties of partially deafferented insect interneurons. J. Neurophysiol. 43: 367382

Murphy, A. D., and S. B. Kater (1978) Specific reinnervation of a target organ by a pair of identified molluscan neurons. Brain Res. 156: 322-328.

Murphy, A. D., and S. B. Kater (1980) Differential discrimination of appropriate pathways by regenerating identified neurons in Helisoma. J. Comp. Neurol. 190: 395-403.

Palka, J., and J. S. Edwards (1973) The cerci and abdominal giant fibers of the house cricket Acheta domesticus. II. Regeneration and effects of chronic deprivation. Proc. $R$. Soc. Lond. (Biol.) 185: 105-121.

Parnas, I., and D. Bowling (1977) Killing of single neurons by intracellular injection of proteolytic enzymes. Nature 270: 626-628.

Pearson, K. G., and A. B. Bradley (1972) Specific regeneration of excitatory motorneurons to leg muscles in the cockroach. Brain Res. 47: 492-496. 
Remler, M., A. Selverston, and D. Kennedy (1968) Lateral giant fibers of crayfish: Location of somata by dye injection. Science 162: 281-283.

Reynolds, E. S. (1963) 'The use of lead citrate at high $\mathrm{pH}$ as an electron-opaque stain in electron microscopy. J. Cell Biol. 17: 208-213.

Selverston, A. I., and D. Kennedy (1969) Structure and function of identified nerve cells in the crayfish. Endeavour 28: 107113.

Uno, Y., and Kwon Chin Soo (1969) Larval development of Macrobrachium rosenbergii (De Man) reared in the laboratory. J. Tokyo Univ. Fish. 55: 179-190.

Uretz, R. B., W. Bloom, and R. E. Zirkle (1954) Irradiation of parts of living cells: II. Effects of ultraviolet microbeam focused on parts of chromosomes. Science 120: 197-199.

van Harrevald, A. (1936) A physiological solution for fresh water crustaceans. Proc. Soc. Exp. Biol. Med. 34: 428-432.

Whitington, P. M. (1979) The specificity of innervation of regenerating motor neurons in the cockroach. J. Comp. Neurol. 186: 456-471.

Wiersma, C. A. G. (1947) Giant nerve fiber system of the crayfish. A contribution to comparative physiology of synapse. J. Neurophysiol. 10: 23-38.

Young, J. Z. (1939) Fused neurons and synaptic contacts in the giant nerve fibers of cephalopods. Philos. Trans. R. Soc. Lond. (Biol.) 229: 465-503. 